\title{
Lag impacts of the anomalous July soil moisture over Southern China on the August rainfall over the Huang-Huai River Basin
}

\author{
Xuan Dong $^{1,2} \cdot$ Yang Zhou ${ }^{1,2}$ (D) Haishan Chen ${ }^{1,2} \cdot$ Botao Zhou $^{1,2} \cdot$ Shanlei Sun ${ }^{1,2}$
}

Received: 14 May 2021 / Accepted: 26 September 2021 / Published online: 16 October 2021

(C) The Author(s) 2021

\begin{abstract}
The effect of soil moisture (SM) on precipitation is an important issue in the land-atmosphere interaction and shows largely regional differences. In this study, the SM of the ERA-Interim reanalysis and precipitation data of the weather stations were used to investigate their relationship over eastern China during July and August. Moreover, the WRF model was applied to further validate the effect of SM on rainfall. In the observations, a significantly negative relationship was found that, when the soil over southern China is wet (dry) in July, the rainfall decreases (increases) over the Huang-Huai-River basin (hereafter HHR) in August. In the model results, the soil can "memorize" its wet anomaly over southern China from July to August. In August, the wet soil increases the latent heat flux at surface and the air moisture at lower levels of the atmosphere, which is generally unstable due to the summer monsoon. Thus, upward motion is prevailing over southern China in August, and the increased surface air moisture is transported upwards. After that, the condensation of water vapor is enhanced at the middle and upper levels, increasing the release of latent heat in the atmosphere. The heat release forms a cyclonic circulation at the lower levels over eastern China, and induces the transport and convergence of water vapor increased over southern China in August. This further strengthens the upward motion over southern China and the cyclonic circulation at the lower levels. Therefore, positive feedback appears between water vapor transport and atmospheric circulation. Meanwhile, the cyclonic circulation over southern China results in a response of water vapor divergence and a downward motion over HHR. Consequently, the negative anomalies of precipitation occur over HHR in August. When the July soil is dry over southern China, the opposite results can be found through the similar mechanism.
\end{abstract}

Keywords Soil moisture $\cdot$ Southern China $\cdot$ Rainfall $\cdot$ Huang-Huai-River Basin $\cdot$ Sensitivity Experiment $\cdot$ Landatmosphere interaction

\section{Introduction}

Soil moisture (SM) plays an important role in the climate system. It can influence the land surface hydrological cycle and energy balance through partitioning surface energy into latent and sensible heat fluxes (Seneviratne et al. 2010).

Yang Zhou

yangzhou@nuist.edu.cn

$\triangle$ Haishan Chen

haishan@nuist.edu.cn

1 Collaborative Innovation Center on Forecast and Evaluation of Meteorological Disasters/Key Laboratory of Meteorological Disaster, Ministry of Education, Nanjing University of Information Science and Technology, Nanjing 210044, China

2 School of Atmospheric Sciences, Nanjing University of Information Science and Technology, No. 219 Ningliu Road, Pukou District, Nanjing 210044, Jiangsu, China Many studies have pointed out that the effects of SM on the atmosphere are significant over the key regions with strong land-atmosphere coupling (Koster et al. 2009; Wei and Dirmeyer 2012). Those regions mainly locate in transition areas, where the soil is neither too dry nor too wet. Recently, southern China is identified as a key region for SM-atmosphere interaction during August due to the sub-seasonal variation of the East Asian summer monsoon (EASM; Zeng and Yuan 2018). This is because the swing of the monsoon rain belt and influence of the subtropical high over eastern China can cause the transition area, in which the soil is 
neither too dry nor too wet. Furthermore, the SM in August could probably inherit its anomaly from previous months because "memory" of SM can last for 20-120 days (Entin et al. 2000; Dirmeyer et al. 2009). Therefore, the July SM can be a potential factor that affects the August precipitation over eastern China.

Through evapotranspiration, SM can significantly affect surface air temperature and precipitation locally. For the surface air temperature, wet (dry) soil increases (decreases) evapotranspiration and cools (warms) surface air (Seneviratne et al. 2010). The impacts of SM on precipitation are complicated. Betts et al. (1994) suggested that large SM increases the surface latent heat flux, which is in favor of occurrence of convective rainfall. Douville et al. (2001) found that the wet soil can increase the rainfall in Africa, but the strong convection increases under the dry soil condition in India. Moreover, the impacts of SM on the precipitation exhibit great differences on various time scales. On the synoptic time scale, the convection is triggered fast under a dry soil condition, but the rainfall lasts longer under the wet soil condition (Cioni and Hohenegger 2017). On the seasonal time scale, the positive SM anomalies in spring lead to the increase of precipitation during the following summer over eastern China (Zhan and Lin. 2011; Zhong et al. 2018). Moreover, Liu et al. (2016) indicated that the relationship is negative between $\mathrm{SM}$ and precipitation on seasonal time scales but positive on the inter-annual time scale at the midlatitudes of the northern Hemisphere during summer. So far, the above-mentioned studies mainly addressed local effects of SM.

Besides local impacts, SM can also influence the atmosphere non-locally (Seneviratne et al. 2010; Koster et al. 2016). Douville (2002) found that the SM anomaly over Europe can cause the transport of dry air from the mid-latitudes to the tropics. Over East Asia, the wet spring soil in lower and middle reaches of the Yangtze River valley can lead to a decline in the summer rainfall over eastern China (Zhang and Zuo 2011; Meng et al. 2014; Liu et al. 2017a,b). Koster et al. (2014) pointed out that the seesaw pattern of SM over northwest America and the Great Plains can trigger atmospheric planetary waves, affecting the surface air temperature over America. Generally, SM can modify the atmospheric circulation or trigger planetary waves, and then induce non-local responses of the atmosphere (Douville 2002; Koster et al. 2014, 2016). Furthermore, anomalies of SM can last for a long period due to its "memory", and induce changes of the thermal condition on the land surface, which causes the lagged responses of the atmosphere nonlocally (Zhang and Zuo 2011; Liu et al. 2017a, b).

SM can affect the precipitation in eastern China both locally and non-locally on different time scales. Liu et al. $(2017 a, b)$ found that there is a positive relationship between the spring and summer precipitation over eastern China, and
$\mathrm{SM}$ is their key connection. Moreover, the spring SM over Indochina has significant influences on the summer rainfall over the Yangtze River basin, which exhibits differently in various conditions of sea surface temperature or in different decades (Gao et al. 2020a, b; Zhu et al. 2021). Zhou et al. (2020) found that the effects of SM on EASM are stronger than those of El Niño, because the SM over eastern China can change the land-sea temperature gradients, which adjusts the strength of the monsoon (Zuo and Zhang 2016). Therefore, SM can be a predictor for the inter-annual variation of the rainfall during EASM (Shi et al. 2021). Previous studies have pointed out that the strong interaction between SM and the atmosphere mainly occurs over several key regions (Koster et al. 2004), but those regions are identified generally on seasonal time scales. Moreover, the influences of the SM over eastern China on the precipitation are regionally dependent during EASM (Zhong et al. 2018). Recently, Zeng and Yuan (2018) pointed out that due to the sub-seasonal variation of EASM, southern China becomes a key region of the strong SM-atmosphere interaction in August. Furthermore, the SM anomaly over southern China in August can be related to the SM anomaly in the previous month due to the SM "memory". Hence, this study attempts to figure out the effects of the SM anomaly over southern China in July on the rainfall changes over the Huang-HuaiRiver basin (HHR) in August.

This paper is organized as follows. Section 2 describes data, methods, and the model experiment design. The relationship between the July SM in southern China and the August rainfall over HHR is presented in Sect. 3. In order to explore the mechanisms behind this relationship, results of numerical sensitivity experiments are provided in Sect. 4 . Lastly, Sect. 5 presents the summary and discussions.

\section{Data and methods}

\subsection{Data}

The 6-hourly ERA-Interim reanalysis (Dee et al. 2011) during 1979-2010 includes the SM at a depth of 0-7 cm, surface air pressure, specific humidity, horizontal winds, and geopotential height. Those data are on 37 pressure levels, except the surface pressure and SM. The horizontal resolution of the data is $1.5^{\circ} \times 1.5^{\circ}$. Besides, data of the US National Centers for Environmental Prediction Climate Forecast System Reanalysis (CFSR; Saha et al., 2010) is at the 6-hourly interval during 1979-2010. This data has $0.5^{\circ} \times 0.5^{\circ}$ horizontal grids on 37 pressure levels. On the land surface, the horizontal resolution of CFSR is about $0.3^{\circ} \times 0.3^{\circ}$ on Gaussian grids. CFSR has four soil depths that are at $0-10 \mathrm{~cm}, 10-40 \mathrm{~cm}, 40-100 \mathrm{~cm}$, and $100-200 \mathrm{~cm}$. The 6-hourly data is averaged into daily mean for further 
analysis. In addition to those reanalyses, the daily precipitation of the 721 weather stations in China during 1979-2010 is provided by the China Meteorological Administration.

Due to lack of long-term ground observation of SM, accuracy of the SM data from reanalysis mostly depends on performance of its land assimilation system. This indicates that usage of the SM from different reanalyses may result in different conclusions. Thus, we conducted the same analysis for both ERA-Interim and CFSR, and very similar results were obtained. For conciseness of this paper and its focus on the effects of SM over southern China, we present the relationship between ERA-Interim SM and station precipitation for the observations. For numerical experiments, CFSR has finer resolution than the ERA-Interim and is used to drive the regional model. Hence, less atmospheric information is lost during interpolation for the lateral boundary conditions of the model.

\subsection{Methods}

The Singular Value Decomposition (SVD) was used to explore the relationship between the July SM and August precipitation over eastern China during 1979-2010 based on the ERA-Interim SM and station precipitation. The precipitation at the 721 stations was interpolated into horizontal grids of $0.5^{\circ} \times 0.5^{\circ}$ through using the Cressman interpolation (Cressman 1959). Furthermore, both the precipitation and SM were standardized through being removed their means and then divided by their standard deviations. After that, SVD was conducted, and its results will be introduced in Sect. 3.

\subsection{Model}

The regional, land-atmospheric coupled model of the Weather Research and Forecasting (WRF) version 4.0 (Skamarock et al. 2008) was adopted to conduct numerical sensitivity experiments. All the experiments were configured with a single domain, which used the Lambert projection on horizontal grids of $50 \times 50 \mathrm{~km}$ (Fig. 1). Instead of a fine resolution, the coarse resolution of $50 \mathrm{~km}$ was used, which could save computation time and is enough for exploring mechanism behind the relationship between SM and precipitation. The schemes of the Rapid Radiative Transfer (Mlawer et al. 1997), the Yonsei University planetary boundary layer (Hong et al. 2006), the WRF single-moment 6-class microphysics (Hong and Lim 2006), and the GrellFreitas ensemble cumulus (Grell and Freitas 2014) were applied in all the experiments. Moreover, the land model used was the Community Land Model version 4 (CLM; Dai et al. 2003; Lawrence et al. 2011). CLM has the soil column of ten layers at the depths from surface to $3.433 \mathrm{~m}$. CFSR was used as model initial and boundary conditions for both atmosphere and land modules, which include variables of air temperature, horizontal winds, relative humidity, and geopotential height at isobaric levels, sea level pressure, surface

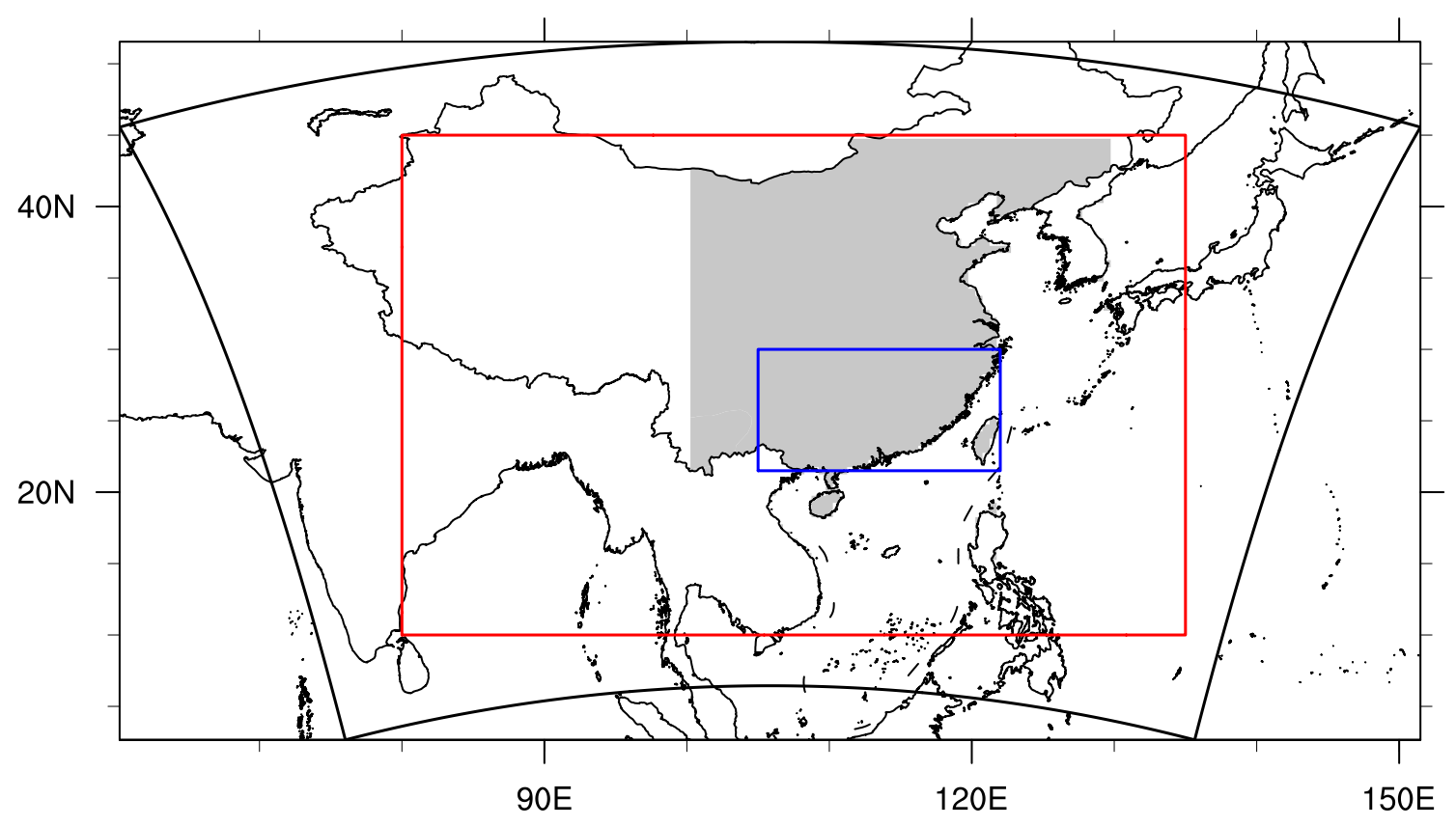

Fig. 1 Model domain (surrounded by black lines). Rainfall is evaluated in the gray shaded area, and atmospheric variables are evaluated in the red rectangle $\left(80^{\circ} \mathrm{E}-135^{\circ} \mathrm{E}\right.$ and $\left.10^{\circ} \mathrm{N}-45^{\circ} \mathrm{N}\right)$ for the WRF model in Fig. 2. The blue rectangle presents the key region of SM $\left(105^{\circ} \mathrm{E}-122^{\circ} \mathrm{E}\right.$ and $\left.21^{\circ} \mathrm{N}-30^{\circ} \mathrm{N}\right)$ over southern China for sensitivity experiments, and is determined by the SVD analysis in Sect. 3 
temperature, 2-m air temperature, 2-m relative humidity, and 10-m horizontal winds, and soil temperature and moisture from 0 to $200 \mathrm{~cm}$ beneath ground surface. The specified boundary width was set to 10 grids $(500 \mathrm{~km})$, which include one grid of specified zone and nine grids of relaxation zone. The semi-Lagrangian interpolation method was used for the lateral boundary condition (Smolarkiewicz 1992).

In order to obtain robust results, each set of experiments contains 256 ensemble members (Table 1). The experiment of each ensemble member was integrated starting from a date during 27 June to 4 July of 1979-2010 ( 8 days $\times 32$ years $=256$ members $)$. The WRF model was integrated from the starting date to 31 August in the experiment of an ensemble member. Therefore, the initial and boundary conditions were varied in different ensemble members. In the first set of experiments, we performed no change in SM, which was freely coupled with other variables, and this experiment is taken as control experiments (CTL). The model outputs were saved at daily interval on 35 sigma levels and further interpolated into 27 pressure levels for analysis.

\subsection{Sensitivity experiments}

In order to investigate the impacts of the July SM over southern China on the August precipitation over HHR, sensitivity experiments were conducted based on the CTL experiment (Table 1). SM anomalies were added in the key region over southern China, which was determined by the significant region in the first SVD mode between the July SM and August rainfall that will be introduced in the next section. The key region is the land area surrounded by the blue rectangle in Fig. 1. Four sets of sensitivity experiments were carried out and denoted as MaxFr, MinFr, MaxFx, and MinFx. In MaxFr and MaxFx (MinFr and MinFx), the July SM at the first three layers $(0-9.1 \mathrm{~cm})$ of soil over the key region in the WRF model was substituted by the maximum (minimum) values of the daily SM of CTL in July. Outside the key region in July, the SM was substituted by the daily, normal output of CTL. During August, in experiments of MaxFr and MinFr, the SM was not substituted by the output of CTL but freely coupled with the other variables. It is noted that in the model experiments, only the SM at the first three layers were substituted, and the beneath soil layers are freely coupled with the surface layers. Thus, the change in surface layers can also vary the SM from subsurface to the root zone, which can alter the evapotranspiration of vegetation in the model.

In the supplement experiments of MaxFx and MinFx, the SM in July was the same as those in MaxFr and MinFr but the SM in August over the entire model domain was substituted by the daily output of CTL. In other words, the SM was not coupled with the atmosphere in MaxFx and MinFx during August, and thus SM "memory" was suppressed. Besides, the supplement experiments of MaxFx and MinFx were conducted only starting on 1 July of each year during 1979-2010. This means that the ensemble members in CTL, MaxFr, and MinFr are 256, but is 32 in MaxFx and MinFx.

All sets of the experiments were configured with the same parameters, integrated over the same periods as those in CTL. It is noted that the initial and boundary conditions varied in different runs in a set of experiments, but the same runs are conducted in different sets of experiments (Table 1). Thus, the only difference among different sets of experiments is SM.

\subsection{Climatology in the WRF Model}

The simulation of rainfall and atmospheric climatology over eastern China was evaluated for the WRF model. Figure 2 presents the Taylor diagram for the precipitation and atmospheric variables averaged during July and August in CTL. The atmospheric variables include the $200-\mathrm{hPa}$ zonal wind, 1000-300 hPa horizontal moisture fluxes, 500-hPa geopotential height, and $850-\mathrm{hPa}$ horizontal winds. The station data was used as the reference for the model precipitation

Table 1 Experiment Design

\begin{tabular}{llllll}
\hline Experiments & Ensemble Members & & \multicolumn{2}{l}{ Soil Moisture } \\
\cline { 2 - 3 } \cline { 5 - 6 } Set Name & Starting Date & Years & Number & July SM & August SM \\
\hline CTL & June 27, June 28, June 29, June 30, July 1, July 2, July 3, July 4 & $1979-2010$ & 256 & Freely Coupled & Freely Coupled \\
MinFr & June 27, June 28, June 29, June 30, July 1, July 2, July 3, July 4 & $1979-2010$ & 256 & Fixed by Min & Freely Coupled \\
MaxFr & June 27, June 28, June 29, June 30, July 1, July 2, July 3, July 4 & $1979-2010$ & 256 & Fixed by Max & Freely Coupled \\
MinFx & July 1 & $1979-2010$ & 32 & Fixed by Min & Fixed by CTL \\
MaxFx & July 1 & $1979-2010$ & 32 & Fixed by Max & Fixed by CTL \\
\hline
\end{tabular}

Five sets of experiments were conducted, including a set of control experiment (CTL) and four sets of sensitivity experiments (MinFr, MaxFr, MinFx, and MaxFx). Except MinFx and MaxFx, each set of the experiments includes 256 runs, which start from different dates in June 27-July 4 during 1979-2010. In CTL, SM is free coupled with the other variables in the model. In the sensitivity experiments, SM in July/August are fixed or substitute by the minimum, maximum, or normal values of the SM in CTL 


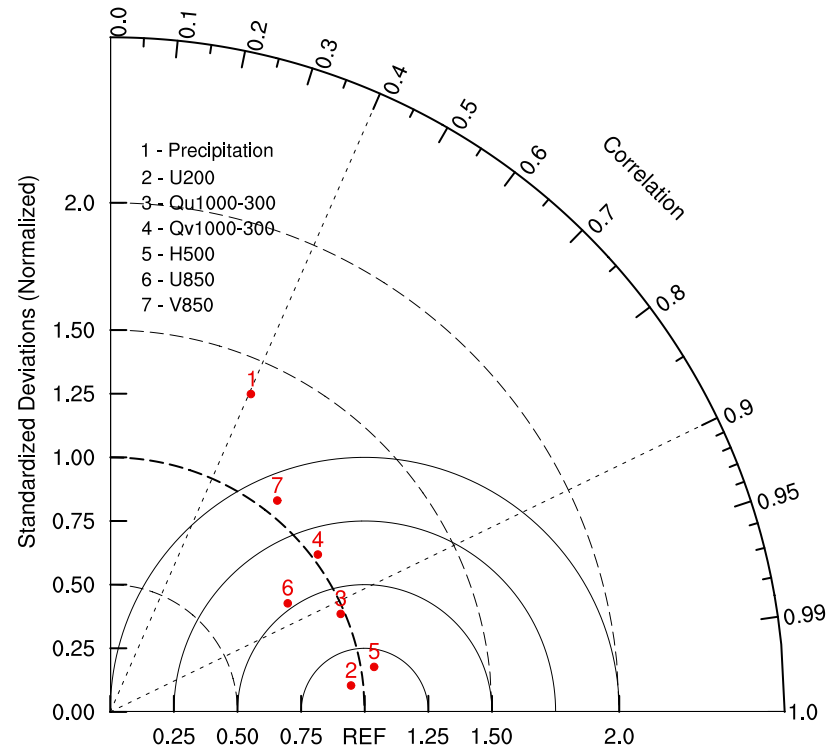

Fig. 2 Taylor diagram of the pattern statistics between the model simulations and observations over the region surrounded by the red rectangle $\left(80^{\circ} \mathrm{E}-135^{\circ} \mathrm{E}\right.$ and $\left.10^{\circ} \mathrm{N}-45^{\circ} \mathrm{N}\right)$ in Fig. 1 , except that the precipitation is evaluated in the gray shaded area in Fig. 1. The diagram is for the variables of precipitation (1), the zonal wind at $200 \mathrm{hPa}$ (2), the horizontal moisture flux integrated from 1000 to $300 \mathrm{hPa}(3$ and 4), the geopotential height at $500 \mathrm{hPa}$ (5), and the zonal (6) and meridional winds at $850 \mathrm{hPa}$ (7). The station precipitation and ERAInterim reanalysis are used as the reference (REF) for the model variables. It is noted that the precipitation to the east of $100^{\circ} \mathrm{E}$ over land in the red rectangle (gray shaded area in Fig. 1) is used to calculate the Taylor diagram

in the Taylor diagram, and the ERA-Interim reanalysis was employed as the reference for atmospheric variables of the model. Before plotting the Taylor diagram, the atmospheric variables in the model were interpolated into the horizontal resolution of $1.5^{\circ} \times 1.5^{\circ}$. The station precipitation was interpolated into the horizontal resolution of $0.5^{\circ} \times 0.5^{\circ}$. In the Taylor diagram, the atmospheric variables over the area surrounded by the red rectangle in Fig. $1\left(80^{\circ} \mathrm{E}-135^{\circ} \mathrm{E}\right.$ and $10^{\circ} \mathrm{N}-45^{\circ} \mathrm{N}$ ) are evaluated, but precipitation is evaluated to the east of $100^{\circ} \mathrm{E}$ over the land of China (gray shaded area in Fig. 1). In addition, all the data are analyzed during 1979-2010 in the Taylor diagram.

In Fig. 2, the spatial correlation between the simulated and observed precipitation is about 0.4 , and the standard deviation of the simulated precipitation is about 1.3 times large of the observations. The centered root-mean-square error for the model precipitation, which is the distance from the reference point in Fig. 2, is the largest among all the model variables. The zonal winds at 850 and $200 \mathrm{hPa}$, geopotential height at $500 \mathrm{hPa}$, and zonal moisture flux have spatial correlations that are greater than 0.85 , and model standard deviations for them are also close to those of the observations. The spatial correlations for the meridional wind and moisture flux are about 0.6 and 0.8 , respectively. On the Taylor diagram, they are farther from the reference point than the other variables, except precipitation. Overall, the WRF model can generally reproduce the climatology of atmospheric circulations during 1979-2010.

Figure 3 shows the spatial and temporal distributions of the observed and simulated precipitation averaged during July and August of 1979-2010. In the observations (Fig. 3a), there are rain belts between 26 and $35^{\circ} \mathrm{N}$ over eastern China and around $22^{\circ} \mathrm{N}$ over southern China. In the model simulation (Fig. 3b), there is a rain belt between 26 and $40^{\circ} \mathrm{N}$, which is farther north and has larger values than that in the observations. In addition, over southern China, the rainfall center is about three degrees farther north (at about $25^{\circ} \mathrm{N}$ ) than that in the observations. The precipitation over the mountain areas between 100 and $110^{\circ} \mathrm{E}$ has much larger values than that in the observations.

The temporal variation of rainfall as functions of time and latitude along $100^{\circ} \mathrm{E}-120^{\circ} \mathrm{E}$ is shown in Fig. 3c, d. In the observations (Fig. 3c), the precipitation persists between 20 and $23^{\circ} \mathrm{N}$ during July-August. Rainfall also happens between 26 and $35^{\circ} \mathrm{N}$ during July but decreases after July. In the model simulation (Fig. 3d), a rainfall center is found at about $25^{\circ} \mathrm{N}$ over southern China during July-August. The rainfall to the north of $25^{\circ} \mathrm{N}$ has the very similar distribution as that of the observation but has much large values. Generally, the simulation of spatial and temporal patterns of rainfall during July-August over eastern China is similar to that of the observations, except that values of the simulated precipitation are large. So far, the simulations of precipitation and meridional circulation during summer still have some biases against the observations over eastern China, which is a common issue confronted by many numerical models (Wang et al. 2013; Giorgi et al. 2012; Huang et al. 2015). The overestimation of the rainfall in the model mainly relates to the cumulus parameter scheme. Previous studies have pointed out that the Grell-Freitas scheme has a better performance than other schemes on monsoon simulation (Jin et al. 2015; Klein et al. 2015; Mugume et al. 2017). However, this scheme usually overestimates the rainfall, which is associated with its overestimation of the heat rate and the model resolution (Gao et al. 2017; Liu et al. 2019).

\section{Relationship between SM and rainfall}

Figure 4 provides the SVDs between July and August for ERA-Interim SM and station rainfall. In Fig. 4a, b, the first heterogeneous mode of SVD can explain about $22.8 \%$ of the total covariance, and mainly represents the relationship between the July SM over southern China and the August precipitation over HHR. The SM (rainfall) pattern in the first SVD mode can explain $14.4 \%$ (9.4\%) of the total variance. 

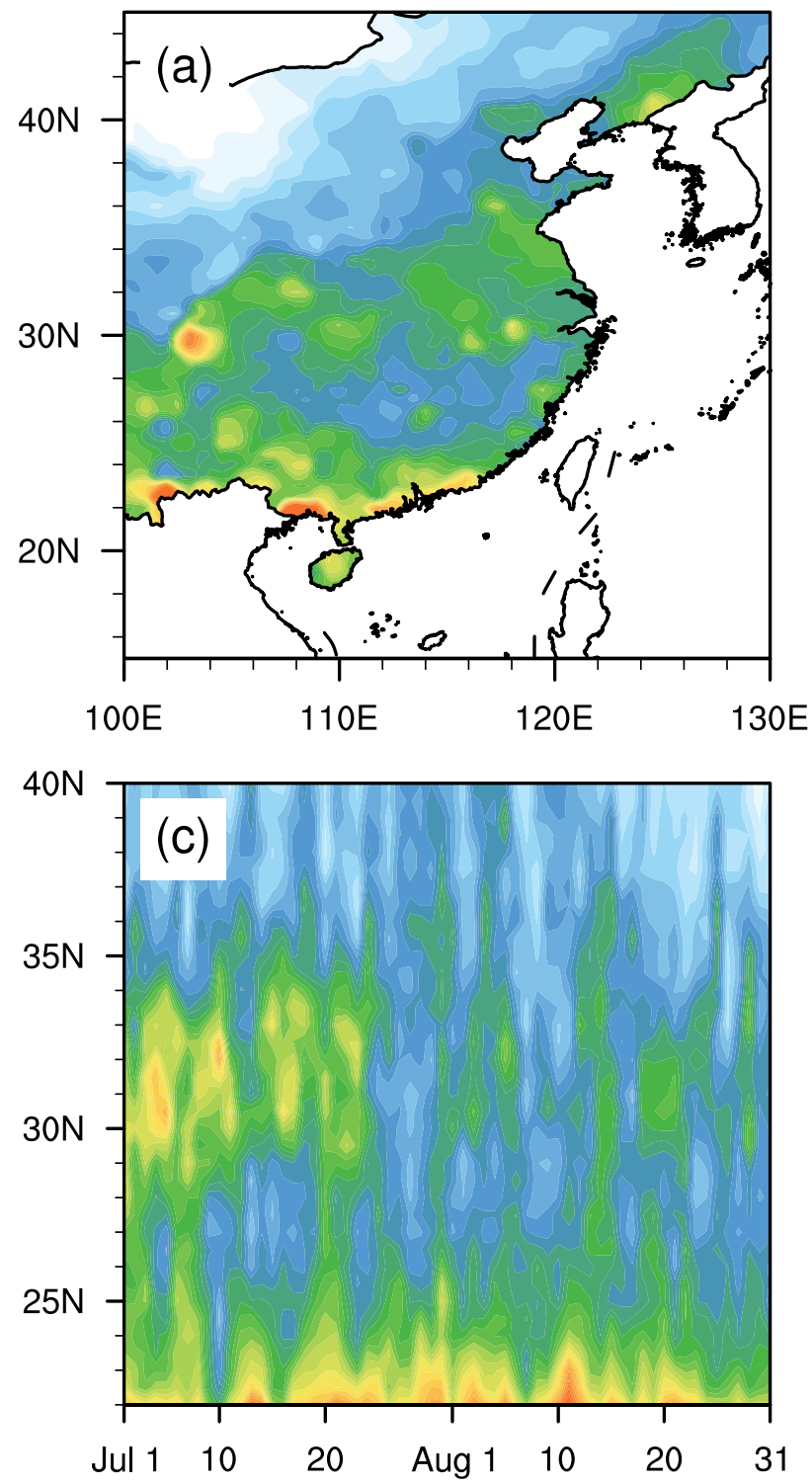

Fig. 3 Spatial distributions of the precipitation climatology (in $\mathrm{mm}$ day $^{-1}$ ) for (a) the weather stations and (b) the model simulation of CTL during July and August over eastern China. The precipitation in

The correlation coefficient is 0.78 for expansion coefficients of the first heterogeneous SVD mode between the SM and precipitation, which is significant at the $5 \%$ level based on the student's $t$ test. The left heterogeneous map for July SM (Fig. 4a) shows that SM anomalies are significantly negative over southern China. A band of positive SM anomalies with several significant grids can be observed to the north of $30^{\circ} \mathrm{N}$. On the right heterogeneous map for August precipitation (Fig. 4b), the anomalies are significantly positive (negative) over HHR (part of southern China) at the $5 \%$ level. If the $10 \%$ level is applied, the rainfall anomalies over most part of the southern China are significant during August. The first mode of SVD indicates a significantly

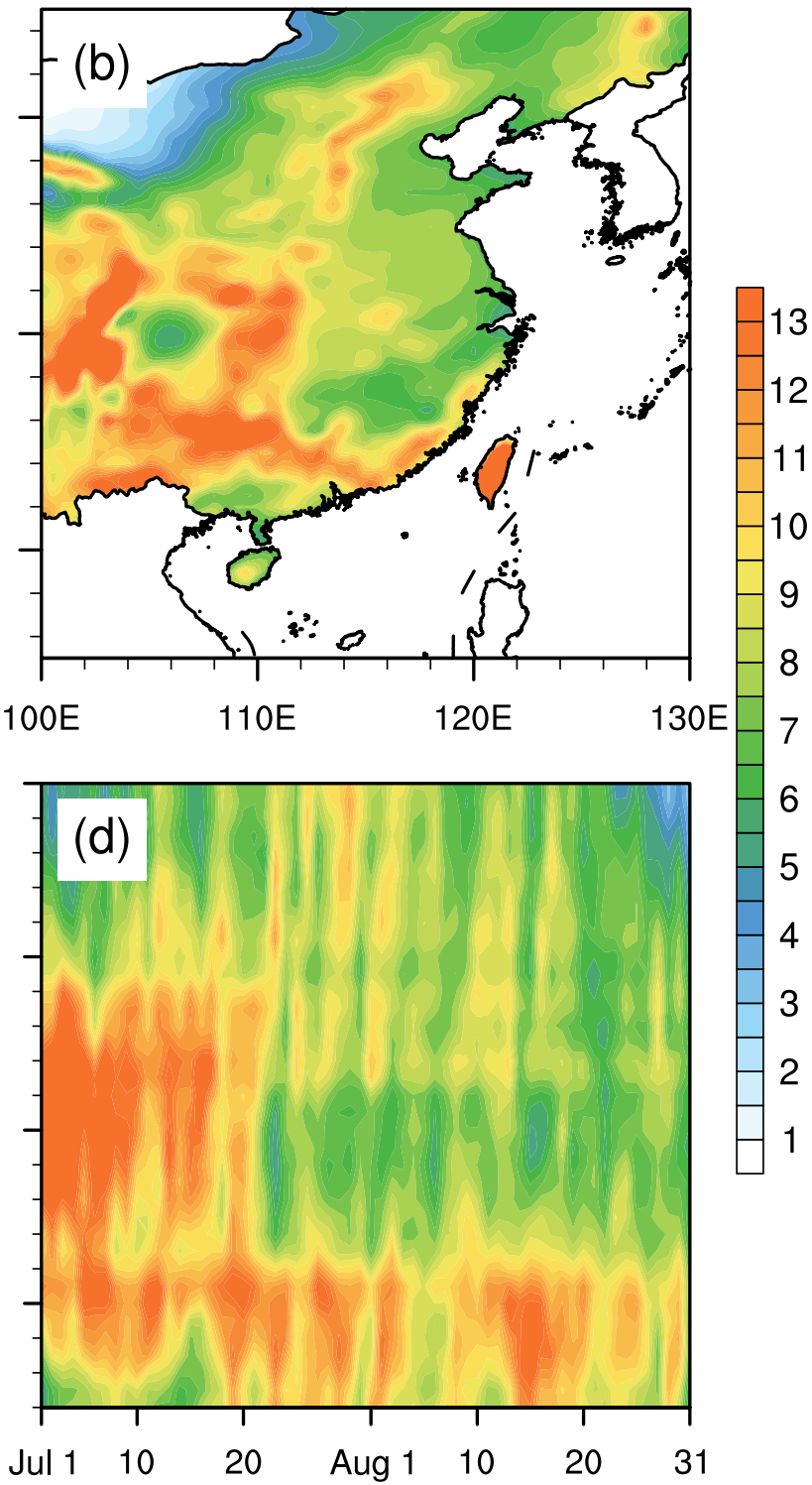

the Hovmöller diagrams is averaged between 100 and $120^{\circ} \mathrm{E}$ during July and August of 1979-2010 for (c) weather stations and (d) the simulation of CTL

negative relationship between the July SM over southern China and the August precipitation over HHR. In order to check whether the first two modes are well separated from each other, the difference of squared covariance between the first two modes is compared with the typical error (North et al. 1982; Zhang and Hendon 1997). It is found that the difference is much larger than the error, and thus the first heterogeneous mode is significantly distinct from the second mode. If first mode significantly separates from the second mode, it means that the first mode can be taken as an identity with independently physical meaning (Zhang and Hendon 1997). Moreover, the second mode of SVD mainly presents the relationship between SM over the lower reaches of the 
Fig. 4 First SVD mode of heterogeneous maps between (a) the July SM and (b) August rainfall over eastern China. This mode explains about $22.8 \%$ of the total covariance and significantly separates from the rest of the modes. Panels (c) and (d) are the first SVD mode of heterogeneous maps between July and August precipitation. The mode explains about $18.9 \%$ of the total covariance but not significantly separates from the rest of the modes. The ERA-Interim SM and station precipitation during 1979-2010 are used. Panels (e) and (f) are the first SVD mode of heterogeneous maps between July and August SM, which explains about $28.1 \%$ of the total covariance.

The correlations shaded in each panel are significant at the 5\% level. The variance explained by each mode to the total variance of that variable is shown on the top left of each panel. The black rectangle in panel (a) surrounds the area of $105^{\circ} \mathrm{E}-122^{\circ} \mathrm{E}$ and $21^{\circ} \mathrm{N}-30^{\circ} \mathrm{N}$ ( $\mathrm{SC}$ is short for southern China), and the rectangle in panel (b) surrounds the area of $103^{\circ} \mathrm{E}-118^{\circ} \mathrm{E}$ and $30^{\circ} \mathrm{N}-38^{\circ} \mathrm{N}$ (HHR). Those two areas will be used in the next figure

\section{$22.8 \%$ covariance}

$14.4 \%$ variance
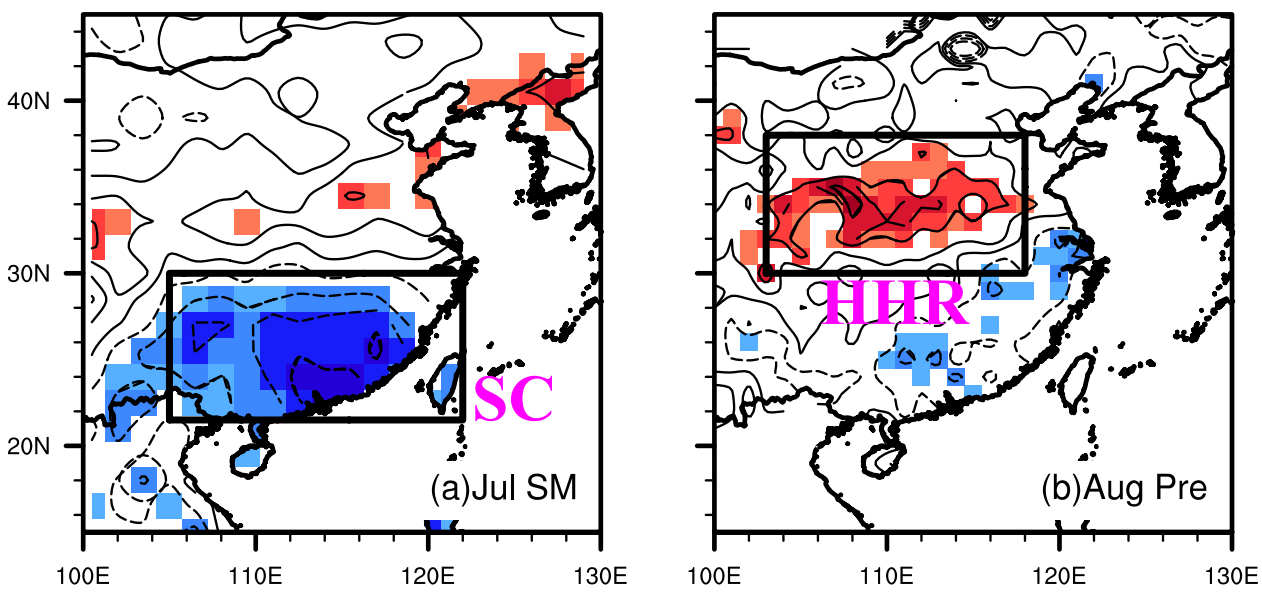

$18.9 \%$ covariance

$10.2 \%$ variance
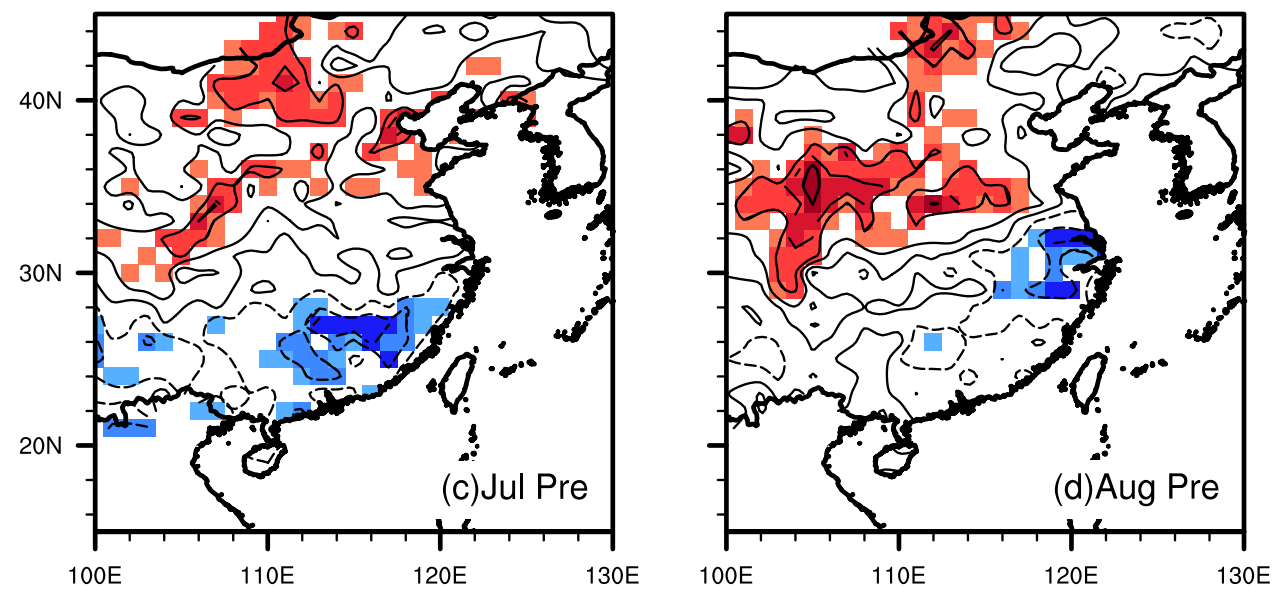

\section{$28.1 \%$ covariance}

$15.8 \%$ variance

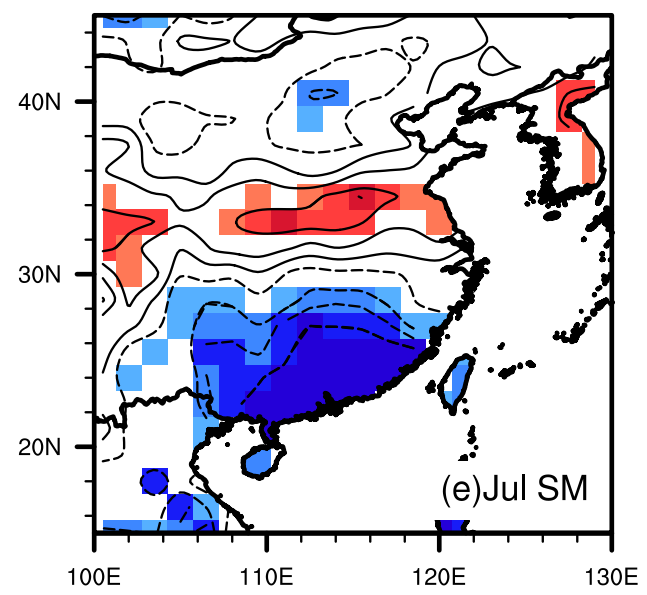

$12.3 \%$ variance

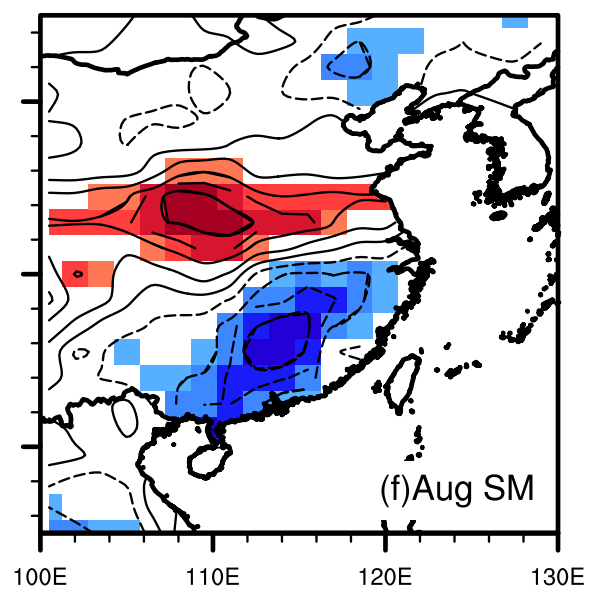

0.6 
Yangtze River valley and precipitation over northern China (figures not shown), which requires further studies.

The relationship between the July SM and August rainfall may reflect an auto-relationship of rainfall between July and August. This relationship maybe caused by a large climate system, and thus the rainfall anomaly could present a consistence from July to August. Figure 4c, d provide the first heterogeneous SVD mode between the precipitation in July and August, which can explain about $18.9 \%$ of the total covariance. The rainfall pattern of July (August) in the first SVD mode can explain $10.2 \%(9.0 \%)$ of the total variance. The correlation coefficient between expansion coefficients of the SVD mode is 0.83 and significant at the $5 \%$ level. The left heterogeneous map for July precipitation (Fig. 4c) shows that there are significantly negative rainfall anomalies over parts of southern China and significantly positive anomalies over northern China. The significant areas in this pattern are not very similar to those of the July SM, except the small area over southern China. On the right heterogeneous map for August precipitation (Fig. 4d), the pattern is generally the same as that shown in Fig. 4b, except that there are some significant rainfall anomalies over eastern Nei Monggol. In addition, the first mode does not well separate from the second mode in the SVD analysis for precipitation according to the test by North et al. (1982).

Figure 4e,f provide the first heterogeneous SVD mode between July and August SM over eastern China. In those maps, the "memory" of SM from July to August can be examined. The first SVD mode can explain $28.1 \%$ of the total covariance, and the correlation coefficient between the expansion coefficients is 0.85 , which is significant at the $5 \%$ level. The SM of the first SVD mode in July (August) can explain $15.8 \%$ (12.3\%) of the total variance of the SM in July (August). The first mode generally shows a seesaw pattern between southern China and HHR in both July and August (Fig. 4e, f). The very similar patterns between the July and August SM anomalies indicate the persistence of SM anomalies over eastern China from July to August.

Figure 5 presents time series of July SM averaged over southern China (the rectangle in Fig. 4a) and August precipitation averaged over HHR (the rectangle in Fig. 4b). Both the precipitation and SM are standardized through being removed their mean and then divided by their standard deviations. The correlation coefficient between the two time series is -0.48 and significant at the $5 \%$ level according to the student's t test. Based on Fig. 5, the differences of the rainfall (Fig. 6a), SM anomaly (Fig. 6b), the moisture divergence and flux (Fig. 6c), the vertical circulation (Fig. 6d), and $\mathrm{Q}_{2}$ (Fig. 6e) in August are calculated between the years with the largely positive and negative SM anomalies over southern China in July. The large SM anomalies are defined as absolute values of SM anomalies greater than or equal to one standard deviation over southern China in July. $\mathrm{Q}_{2}$

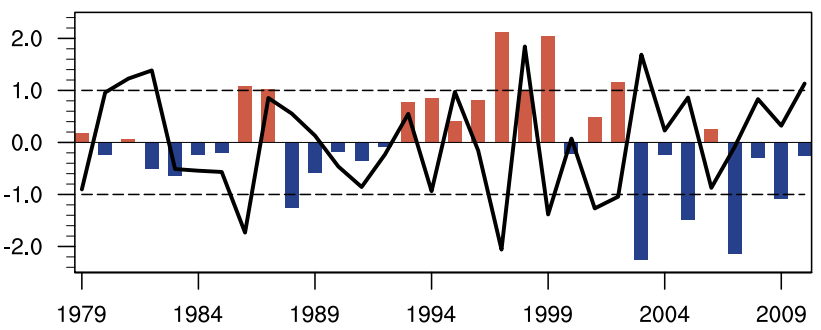

Fig. 5 Time series of the July SM (bar) over southern China and August precipitation (curve) over HHR. Those two regions are defined in Fig. 4a, b (rectangles). Both the SM and precipitation are standardized, and the dash lines indicate one standard deviation

refers to the heat associated with apparent moisture sink (in $\mathrm{K}$ day $^{-1}$ ), and mainly represents heat caused by condensation of water vapor in the atmosphere (Yanai et al. 1973).

Figure 6a shows that when the SM is large over southern China in July, the rainfall decreases significantly at the 5\% level over HHR in August. The rainfall anomalies are positive but only significant over small parts of southwestern China. Figure $6 \mathrm{~b}$ presents the difference of SM in August. The significantly negative (positive) differences are found over HHR (part of southern China). In Fig. 6c, the significant divergence (convergence) of air moisture at $850-500 \mathrm{hPa}$ occurs between $30^{\circ} \mathrm{N}$ and $40^{\circ} \mathrm{N}$ (part of southern China) during August, which is in favor of the rainfall decrease (increase). The air moisture convergence is calculated according to Trenberth (1991). The air moisture flux between 850 and $500 \mathrm{hPa}$ is shown by the vectors in Fig. 6c. The transfer of water vapor significantly decreases from southern China to HHR. Moreover, an anticyclonic (a cyclonic) moisture flux has a center over the South China Sea (the Yellow Sea). Figure 6d provides the vertical circulation and velocity averaged along $111^{\circ} \mathrm{E}$ as functions of latitude and height. An upward (downward) motion is found at about $18^{\circ} \mathrm{N}-22^{\circ} \mathrm{N}\left(30^{\circ} \mathrm{N}-40^{\circ} \mathrm{N}\right)$ below $300 \mathrm{hPa}$, and south (north) wind increases at about $200 \mathrm{hPa}(850 \mathrm{hPa})$. The downward motion is significant at the $5 \%$ level (shaded areas in Fig. 6d), but the upward motion is significant at the $10 \%$ level (significance is not shown). As shown by Fig. 6e, the significant increase of $\mathrm{Q}_{2}$ is mainly found around $25^{\circ} \mathrm{N}$ between 500 and $200 \mathrm{hPa}$. The significant decrease of $\mathrm{Q}_{2}$ is around $32^{\circ} \mathrm{N}$ between 850 and $500 \mathrm{hPa}$.

Generally, when SM anomalies are positive over southern China in July, the air moisture flux and the vertical circulation suppress the rainfall between 30 and $40^{\circ} \mathrm{N}$ in August. However, it is still difficult to conclude whether the rainfall change in August is a consequence of the SM anomaly in July. The relationship between the SM and rainfall may just be a reflection of their responses to another climatic factor. Therefore, sensitivity experiments using the WRF model were conducted 

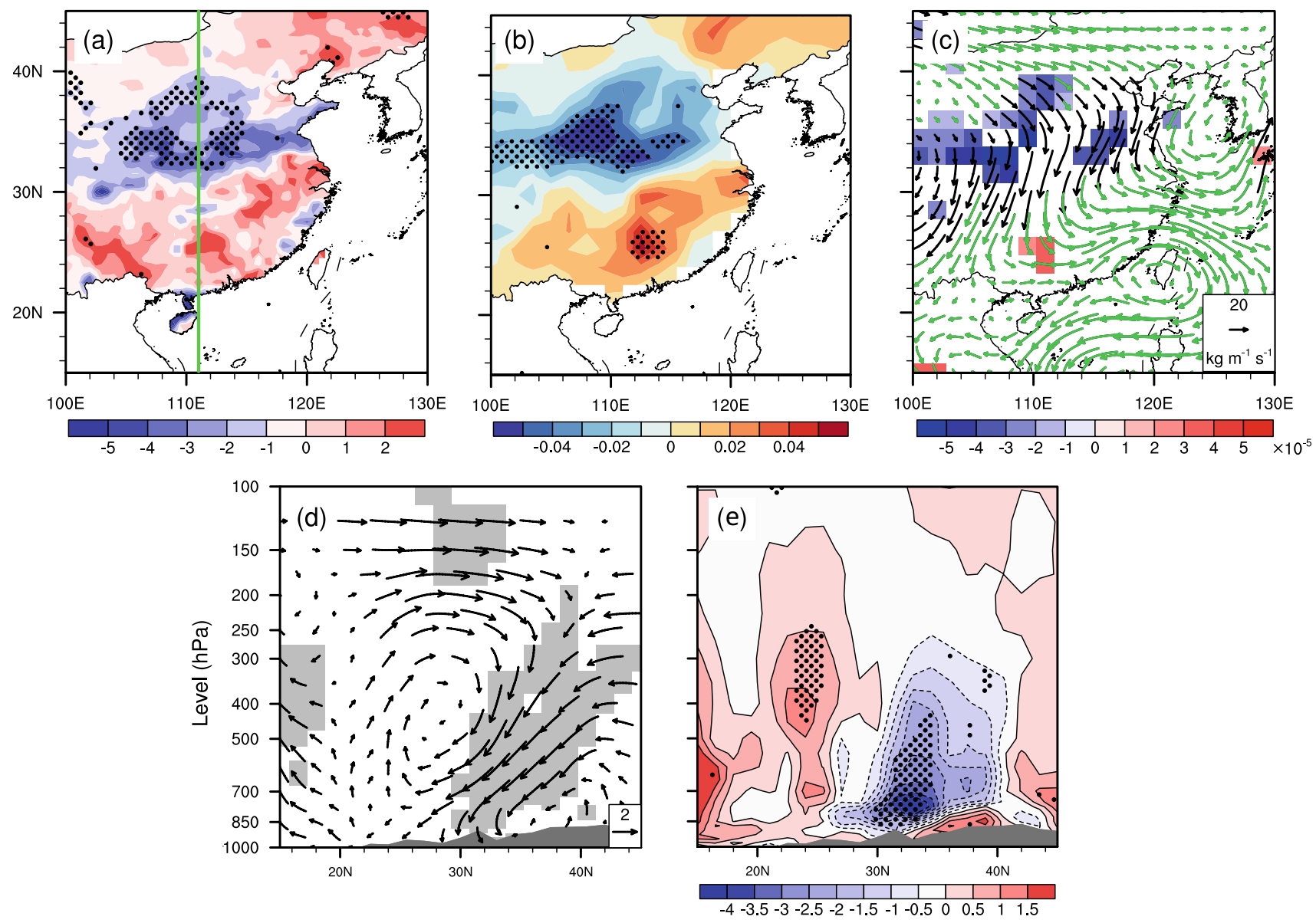

Fig. 6 Differences of August (a) precipitation (in $\mathrm{mm} \mathrm{day}^{-1}$ ), (b) the $\mathrm{SM}$ anomaly (in $\mathrm{m}^{3} \mathrm{~m}^{-3}$ ), (c) the moisture convergence (shaded; $10^{-5} \mathrm{~kg} \mathrm{~s}^{-1}$ ) and flux (vector; $\mathrm{kg} \mathrm{m}^{-1} \mathrm{~s}^{-1}$ ) at $850-500 \mathrm{hPa}$, (d) the vertical velocity (shaded; $\mathrm{Pa} \mathrm{s}^{-1}$ ) and circulation (vector), and (e) $\mathrm{Q}_{2}$ (in $\mathrm{K} \mathrm{day}^{-1}$ ) between the years with July SM anomalies greater and smaller than one standard deviation. The vertical circulation and $\mathrm{Q}_{2}$

are the cross section along $111^{\circ} \mathrm{E}$ (green line in panel a), and the vertical velocity is multiplied by -50 . In panels $(\mathbf{a}),(\mathbf{b})$, and (e), grids with black dots indicate the differences are significant at the 5\% level based on the student's t test. In panel (c), vectors with black color are significant at the 5\% level. In panels (d) and (e), the shaded areas are also significant at the $5 \%$ level

to further examine the relationship between July SM and August rainfall and will be presented in the next section.

It is noted that the SM at the depth of $0-7 \mathrm{~cm}$ is used to explore the relationship between SM and rainfall. However, in surface soil, the part that is impacted by atmospheric systems has shorter "memory" than the soil from subsurface to the root zone. The result from the analysis of surface SM is a reflection of the effect of SM from deep layers. In next section, the changes of surface SM in the sensitivity experiments include the effect of SM in the root zone, because surface SM anomalies can permeate into the deep layers. In the following, we present results of the experiments with surface SM changed.

\section{Model results}

\subsection{Precipitation anomalies}

The differences of precipitation in August between experiments of MaxFr and MinFr are firstly examined (Fig. 7a). Each pair of the sensitivity experiments shares the same initial and boundary conditions, and thus the rainfall changes in August are mainly caused by the differences in the July SM over southern China. In Fig. 7a, the differences on the grid points with black dots are significant at 

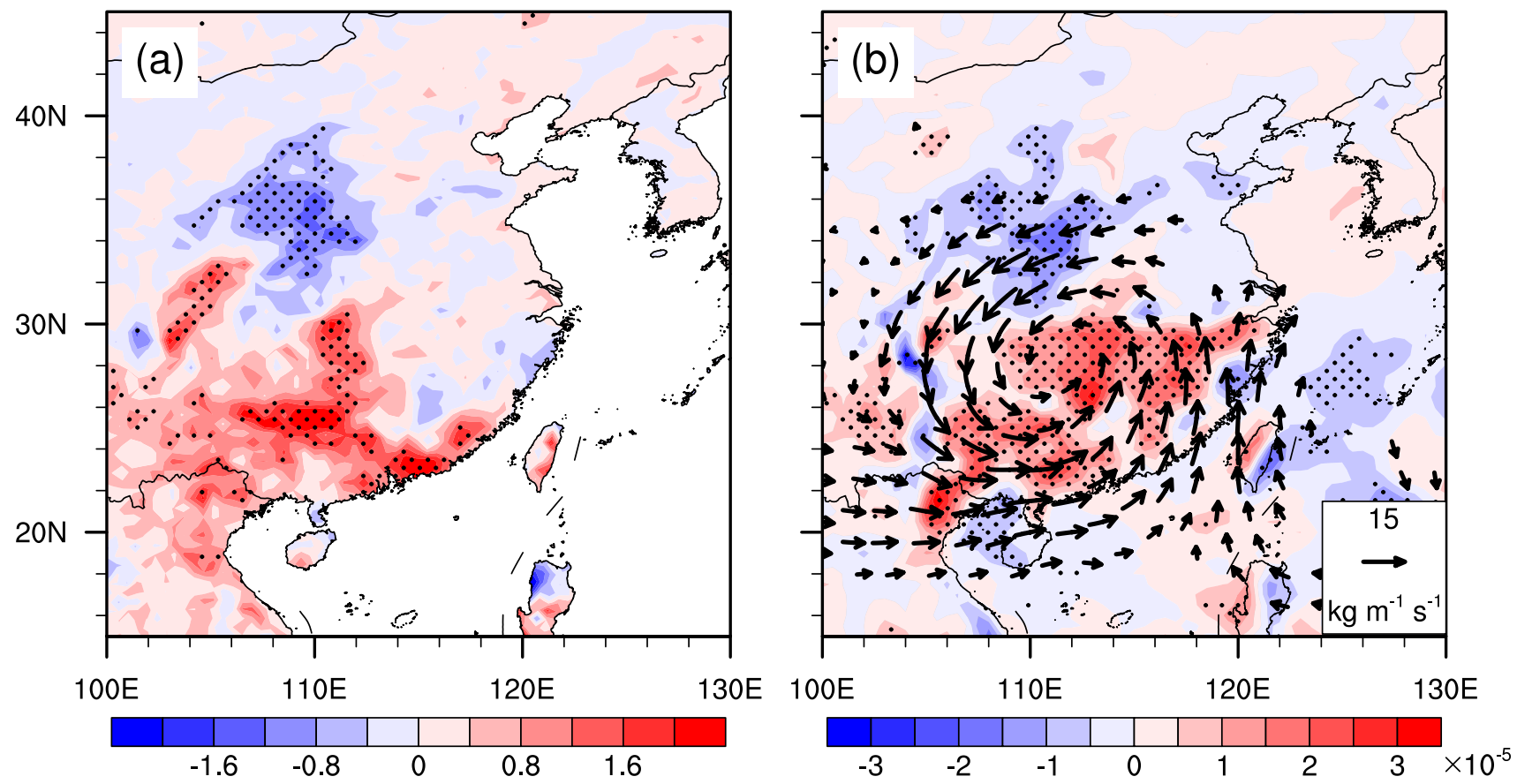

Fig. 7 Differences of the (a) precipitation (in mm day ${ }^{-1}$ ), (b) moisture convergence (shaded; $10^{-5} \mathrm{~kg} \mathrm{~s}^{-1}$ ) and flux (vector; $\mathrm{kg} \mathrm{m}^{-1} \mathrm{~s}^{-1}$ ) in the sensitivity experiments between MaxFr and MinFr in August. Grids with black dots are significant at the 5\% level according to the student's $t$ test

the 5\% level based on the student's t test. There are significantly positive (negative) differences of precipitation over southern China (between 30 and $40^{\circ} \mathrm{N}, \mathrm{HHR}$ ) in August. Figure 7a indicates that when the July soil is wet (dry) over southern China, the precipitation significantly increases (decreases) over southern China (HHR) in August. This is generally consistent with the results of the observations (Fig. 4-6), except that the rainfall anomalies are farther west than those in the observations. This is mainly associated with the strong subtropical high in the model (figures not shown), which is further north and west in the model than that in the observations. This causes rainfall centers farther northwest in CTL than those in the observations (Fig. 3b).

The differences of the moisture convergence and flux between MaxFr and MinFr during August are presented in Fig. 7b. The moisture convergence and flux are integrated from 850 to $500 \mathrm{hPa}$, and color shaded areas are significant at the 5\% level based on the student's t test. In Fig. 7b, the air moisture is significantly convergent (divergent) over southern China (HHR). There is a cyclonic moisture flux with a center at about $114^{\circ} \mathrm{E}$ and $30^{\circ} \mathrm{N}$. The cyclonic circulation decreases (increases) the transfer of water vapor from southern China to northern China (from the South China Sea to southern China). The moisture convergence and flux lead to the increase (decrease) of precipitation over southern China (HHR). This also agrees with those of the observations shown in Fig. 6c, but the cyclonic circulation is farther east in the observations. Overall, when the July soil is wet over southern China, the transport of water vapor to southern China (HHR) increases (decreases), and air moisture is convergent (divergent) over southern China (HHR) at $850-500 \mathrm{hPa}$. This can cause positive (negative) precipitation anomalies over southern China (HHR).

\subsection{Anomalous circulation}

Figure 8a provides the differences of the geopotential height and horizontal winds at $700 \mathrm{hPa}$ in August between MaxFr and MinFr. The geopotential height and horizontal winds at $700 \mathrm{hPa}$ can generally represent the horizontal circulation between 850 and $500 \mathrm{hPa}$. In Fig. 8a, there are significantly negative (positive) anomalies of geopotential height with a center at about $111^{\circ} \mathrm{E}$ and $28^{\circ} \mathrm{N}$ (to the east of Taiwan). The negative (positive) anomalies of geopotential height correspond to the cyclonic circulation over eastern China. The cyclonic wind vectors are also significant at the 5\% level. The horizontal circulation at $700 \mathrm{hPa}$ agrees with the moisture flux between 850 and $500 \mathrm{hPa}$, as shown in Fig. 7b.

Figure $8 \mathrm{~b}$ shows cross sections of the vertical velocity $(\omega)$ and circulation differences between MaxFr and MinFr along $111^{\circ} \mathrm{E}$. In Fig. 8 b, the vertical circulation shows a significant increase (decrease) of upward motion over southern China (HHR). Figure $8 \mathrm{c} 1$ presents the cross section of the 

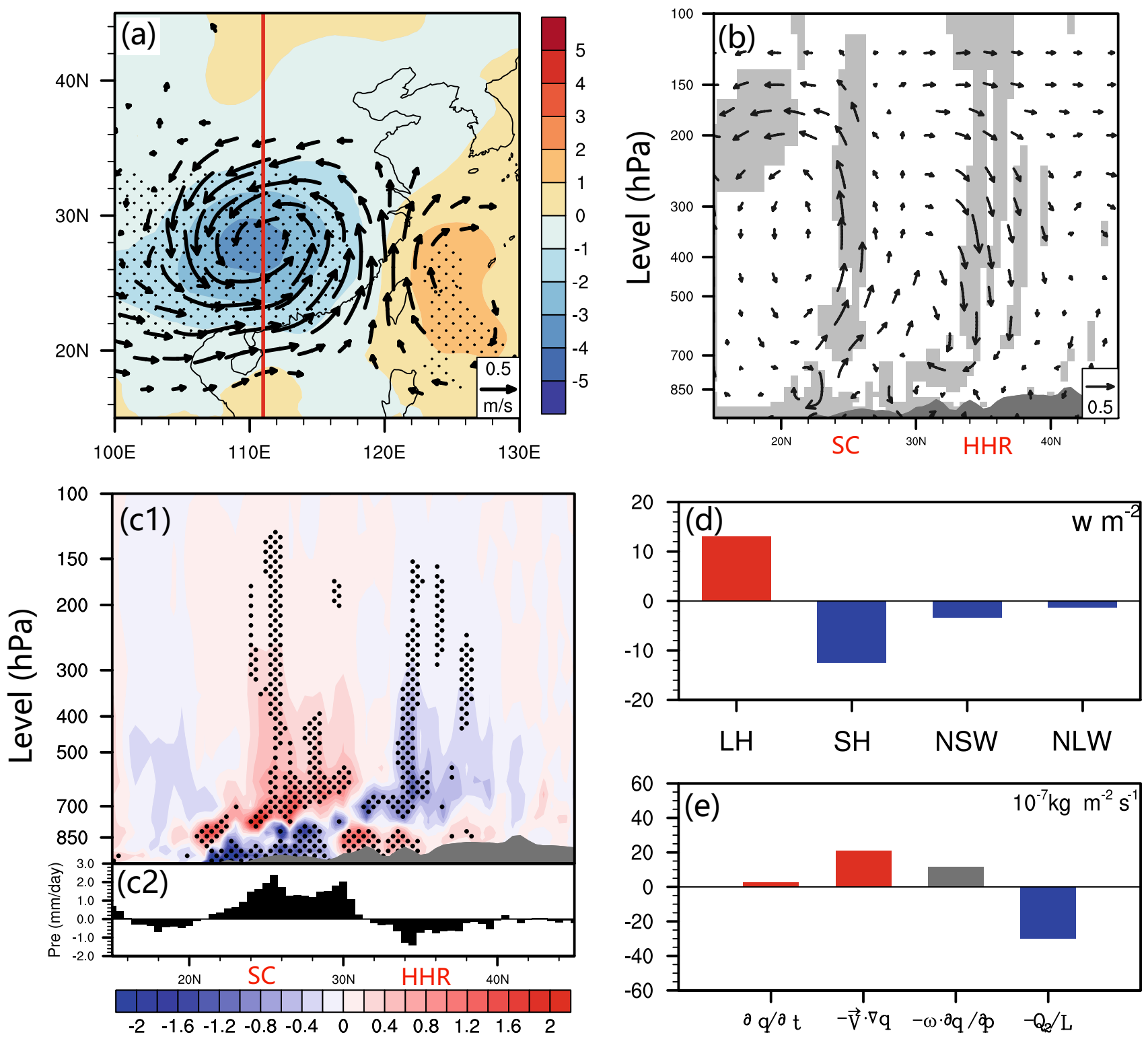

Fig. 8 Same as Fig. 7 in August, but for (a) geopotential height (shaded; in gpm) and horizontal winds (vector; $\mathrm{m} \mathrm{s}^{-1}$ ) at $700 \mathrm{hPa} . \mathbf{b}$ The vertical circulation (vector; vertical velocity is multiplied by 50) and velocity (shaded; in $\mathrm{Pa} \mathrm{s}^{-1}$ ) along $111^{\circ} \mathrm{E}$ (red line in panel a). $\mathbf{c} 1$ The heat associated with apparent water sink (shaded; $\mathrm{Q}_{2}$ in $\mathrm{K}$ day $^{-1}$ ) along $111^{\circ} \mathrm{E}$. $\mathrm{c} 2$ The precipitation (in $\mathrm{mm} \mathrm{day}^{-1}$ ) along $111^{\circ} \mathrm{E}$. d The surface latent and sensible heat fluxes, and net surface short and long wave radiation (in $\mathrm{W} \mathrm{m}^{-2}$ ) in Eq. (1) are averaged over the

key region. e The water vapor tendency, horizontal advection of water vapor, vertical advection of water vapor, and apparent water sink (in $10^{-7} \mathrm{~kg} \mathrm{~m}^{-2} \mathrm{~s}^{-1}$ ) in Eq. (2) between 850 and $500 \mathrm{hPa}$ in the key region over southern China. The grid points with black dots in panels (a)-(c) are significant at the 5\% level based on the student's t test. The bar in panels (d) and (e) with gray color are not significant, but the remains are significant at the $5 \%$ level based on the student's $t$ test

differences of $\mathrm{Q}_{2}$ between $\mathrm{MaxFr}$ and MinFr. There are significantly positive $\mathrm{Q}_{2}$ anomalies at $850-500 \mathrm{hPa}$ between 26 and $32^{\circ} \mathrm{N}$ and significantly negative $\mathrm{Q}_{2}$ anomalies between 30 and $40^{\circ} \mathrm{N}$ above $700 \mathrm{hPa}$. Below $700 \mathrm{hPa}, \mathrm{Q}_{2}$ anomalies are on the opposite. Figure $8 \mathrm{c} 2$ provides the corresponding precipitation on the ground. The increase (decrease) of precipitation occurs with the increase (decrease) of the upward motion and $\mathrm{Q}_{2}$.
Figures 8d and e present the energy balance on the land surface (Eq. 1) and the water vapor budget in the atmosphere (Eq. 2) in the key region over southern China in August, respectively. In Eq. 1, GF is the total net flux on the ground; LH is the surface latent heat flux; $\mathrm{SH}$ is the surface sensible heat flux; NSW is net shortwave radiation; and NLW is net longwave radiation. All the upward fluxes are positive. 
$\mathrm{GF}=\mathrm{LH}+\mathrm{SH}+\mathrm{NSW}+\mathrm{NLW}$

$\frac{\partial q}{\partial t}=-\overrightarrow{\mathbf{V}} \cdot \nabla q-\omega \frac{\partial q}{\partial p}-\frac{Q_{2}}{L}$

In Eq. 2, $q$ is specific humidity (in $\mathrm{kg} \mathrm{kg}^{-1}$ ), $\overrightarrow{\mathbf{V}}$ is the horizontal wind vector (in $\mathrm{m} \mathrm{s}^{-1}$ ), $\omega$ is the vertical velocity (in $\mathrm{Pa} \mathrm{s}^{-1}$ ), $p$ is air pressure (in $\mathrm{Pa}$ ), and $L$ is the latent heat during the water phase change (in $\mathrm{J} \mathrm{kg}^{-1}$ ). The left term $\left(\frac{\partial q}{\partial t}\right)$ in Eq. 2 is the tendency of atmospheric water vapor; the first right term $(-\mathbf{V} \cdot \nabla q)$ is the horizontal advection of water vapor; the second right term $\left(-\omega \frac{\partial q}{\partial p}\right)$ is the vertical advection of water vapor; and the last term $\left(-\frac{Q_{2}}{L}\right)$ on the right is sink of water vapor.

In Fig. 8d, there are significantly positive LH, negative $\mathrm{SH}$, negative NSW, and negative NLW anomalies in the key region over southern China in August. Figure 8e presents the water balance between 850 and $500 \mathrm{hPa}$ in the key region over southern China. In the atmosphere, there are significantly positive (negative) anomalies of the horizontal water vapor advection (moisture sink) over southern China in August. The moisture change associated with the vertical motion is not significant. Thus, the water vapor tendency is significantly positive and associated with the horizontal advection. Figures $8 \mathrm{~d}$ and e present that the wet soil in July can increase surface latent heat in August, and the water vapor in the atmosphere between 850 and $500 \mathrm{hPa}$ is significantly induced by horizontal advection of water vapor in August.

\subsection{Possible mechanism}

Figures 9a, c further present cross sections of the vertical circulation, equivalent potential temperature $\left(\theta_{\mathrm{se}}\right)$, and vertical advection of water vapor ( $\left.-\omega \frac{\partial q}{\partial p}\right)$ during August for the ERA-Interim (Fig. 9a) and the experiments of MinFr (Fig. 9c). The differences of vertical advection of water vapor between the two experiments are shown in Fig. 9d, and its counterpart in the observations is shown in Fig. 9b, which uses the similar method as that shown in Fig. 6. In ERA-Interim (Fig. 9a), there are upward and south (north) winds from 10 to $35^{\circ} \mathrm{N}$ below (above) $400 \mathrm{hPa}$, which is part of the monsoon circulation over eastern China. In Fig. 9a, the vertical transport of water vapor between 20 and $40^{\circ} \mathrm{N}$ (shading) is generally upward. Moreover, $-\frac{\partial \theta_{s e}}{\partial p}$ is negative from 1000 to $500 \mathrm{hPa}$ to the south of $35^{\circ} \mathrm{N}$, which means the atmosphere is unstable at low levels over southern China in August. The same patterns are also found in MinFr (Fig. 9c), except that the upward motion to the south (north) of $20^{\circ} \mathrm{N}$ above $700 \mathrm{hPa}$ is weaker (stronger) than that in ERAInterim. Furthermore, the upward motion in the two experiments is farther north than that in ERA-Interim. This indicates a stronger monsoon in the model. In both the model results and observations, the upward motion and instability of the atmosphere at lower levels in the summer monsoon are in favor of the upward transfer of water vapor, except that several areas below $700 \mathrm{hPa}$ have the downward transfer of water vapor. The differences of the vertical advection of water vapor between MaxFr and MinFr are shown in Fig. 9d. Although the average of vertical advection of water vapor is not significant in Fig. 8e, the positive anomaly in a vertical section plane is significantly found between 20 and $30^{\circ} \mathrm{N}$ above $700 \mathrm{hPa}$ (Fig. 9d). Compared Fig. 9a,c, it is found that the vertical moisture advection is stronger and reach much higher than those in the observation. Due to the strong monsoon in the model, the anomalies of vertical advection reach higher levels (Fig. 9d) than those in the observations (Fig. 9b). The significant decrease of vertical advection is generally found between 30 and $40^{\circ} \mathrm{N}$ above $700 \mathrm{hPa}$ (between 20 and $30^{\circ} \mathrm{N}$ below $700 \mathrm{hPa}$ ). The increase of the upward advection of air moisture corresponds to the increase of $\mathrm{Q}_{2}$ anomalies and further triggers the formation of cyclonic circulation over eastern China.

Figure 10a presents the averaged SM in the key region from July to August for the experiments of CTL, MaxFr, and MinFr. SM varies from 4 July to 31 August. Over the key region in July, the SM in MaxFr (MinFr) is fixed and greater (smaller) than that in CTL. In August, the SM in the model is not fixed by the SM in CTL and fully coupled with the atmosphere. Due to "memory" of SM, the SM in MaxFr (MinFr) is still greater (smaller) than that in CTL. This agrees with the observations (Figs. $4 \mathrm{e}-\mathrm{h}$ and $6 \mathrm{~b}$ ). Figure $10 \mathrm{~b}$ shows the differences of SM between MaxFr and MinFr over the region between 105 and $122^{\circ} \mathrm{E}$, and the shaded areas are significant at the $5 \%$ level based on the student's $\mathrm{t}$ test. Figure $10 \mathrm{~b}$ further presents that the SM over southern China in August can significantly "memorize" the anomalies in July. Hence, over southern China, when the SM increases in July, the latent heat on the surface increases but the sensible heat decreases in August (Fig. 8d). Therefore, the air moisture at low levels is increased (Fig. 10c), which provides more water vapor to the atmosphere. Due to the circulation and instability of the low-level atmosphere in the monsoon, the upward motion and vertical advection of water vapor generally occur over southern China in August (Fig. 9a, c). The increase of air moisture causes the release of latent heat at the lower and middle levels over southern China (Fig. 8c1). This heat leads to the increase of upward motion (Fig. 8b) and the formation of a cyclonic anomalous circulation at $700 \mathrm{hPa}$ (Fig. 8a). The circulation increases the horizontal advection of moisture to southern China (Fig. 7b and 8e), and the upward motion over southern China and the downward motion over HHR (Fig. 8b) are enhanced. The downward motion and moisture divergence are not in favor of the precipitation over HHR. 

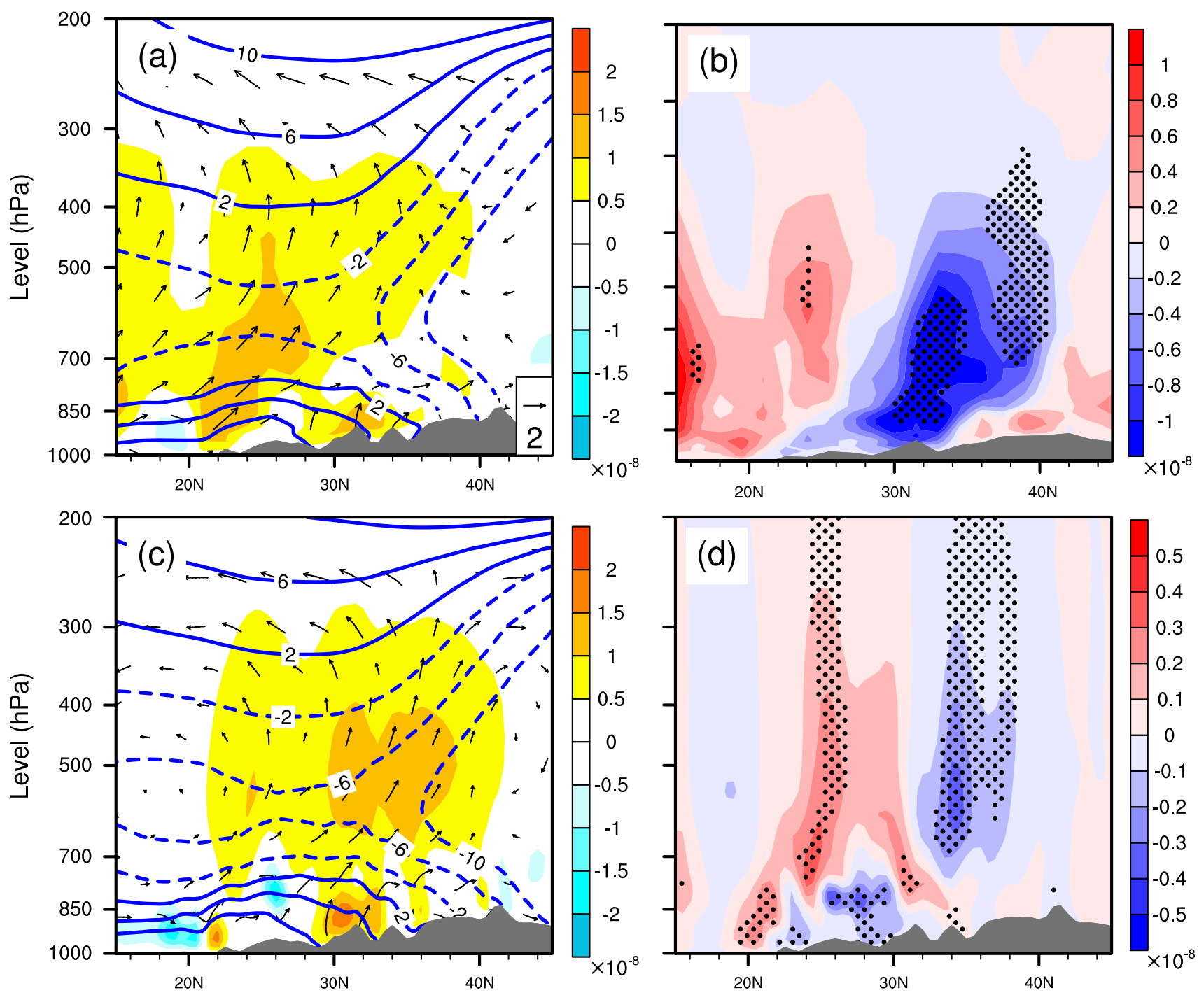

Fig. 9 Vertical circulation (vector), equivalent potential temperature $\left(\theta_{\mathrm{se}}\right.$, contour in $\left.\mathrm{K}\right)$ and advection of air moisture (shaded; in $\mathrm{kg}$ $\mathrm{kg}^{-1} \mathrm{~s}^{-1}$ ) along $111^{\circ} \mathrm{E}$ in (a) ERA-Interim and (c) MinFr. The $\theta_{\mathrm{se}}$ in each panel of (a) and (c) is the deviations from the average of $\theta_{\text {se }}$ along the section of $111^{\circ} \mathrm{E}$ at $1000-200 \mathrm{hPa}$. The averages of $\theta_{\text {se }}$ are $342.56 \mathrm{~K}, 342.04 \mathrm{~K}$, and $342.16 \mathrm{~K}$ for panel (a) and (c), respectively.

To further check whether the rainfall change in HHR is closely related to the SM memory over southern China, another two sets of supplement experiments are conducted. They are MaxFx and MinFx (Fig. 10d), which have been introduced in Sect. 2. In those two experiments, when the SM in August is fixed by the SM of CTL in August, which means the SM is not coupled with the atmosphere. Thus, the SM anomalies in July cannot persist in August anymore. Figure 10d shows the rainfall differences in August between MaxFx and MinFx. Only few areas can be found with significant differences of precipitation in Fig. 10d, which is generally different from the observations (Fig. 6a). Generally, it can be concluded that the negative relationship between the $\mathbf{b}, \mathbf{d}$ the vertical advection of water vapor along $111^{\circ} \mathrm{E}$. Panel (b) is for the observations, which is obtained through the similar computation to Fig. 6, and panel (d) is the differences between MaxFr and MinFr. The dotted areas are significant at 5\% level based on the student's $t$ test

July SM over southern China and the August rainfall over HHR is a result of the SM "memory" over southern China.

\section{Summary and discussions}

In this study, the ERA-Interim SM and station precipitation data during 1979-2010 were used to perform SVD and the composite analysis. A significantly negative relationship is identified between the July SM over southern China and the August precipitation over HHR. In other words, when soil is wet (dry) over southern China in July, the precipitation significantly decreases (increases) over HHR in 

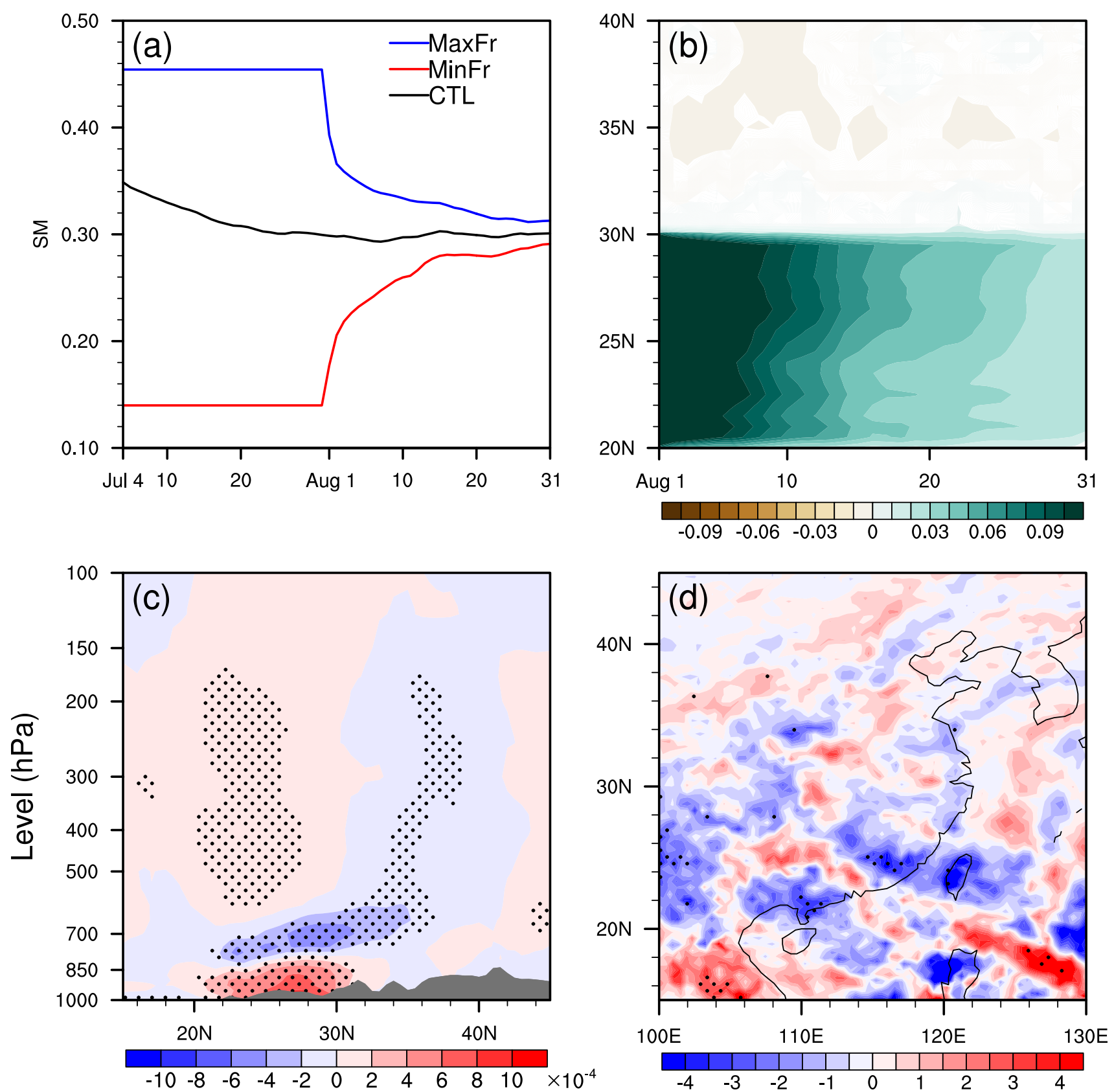

Fig. 10 a Anomalies of $\mathrm{SM}\left(\mathrm{m}^{3} \mathrm{~m}^{-3}\right)$ averaged in the key region over southern China. The blue, black, and red lines indicate the SM in the experiments of MaxFr, CTL, and MinFr, respectively. Panel (b) is the differences of SM between MaxFr and MinFr over the key region and to the north of the key region (between $105^{\circ} \mathrm{E}-122^{\circ} \mathrm{E}$ ) as the functions of latitude and time in August, and shaded areas are significant at the 5\% level based on the student's t test. Panel (c) shows differ-

August. In composites of the moisture divergence and flux at $850-500 \mathrm{hPa}$, it is found that when the July SM is large over southern China, air moisture is convergent (divergent) over southern China (HHR) in August. In addition, the transport of atmospheric water vapor to southern China (HHR) increases (decreases) at 850-500 hPa. Furthermore, over ences between the specific humidity $\left(\mathrm{kg} \mathrm{kg}^{-1}\right)$ in $\mathrm{MaxFr}$ and $\mathrm{MinFr}$ along the section of $111^{\circ} \mathrm{E}$. Panel (d) shows the differences of precipitation $\left(\mathrm{mm} \mathrm{day}^{-1}\right.$ ) in August between MaxFx and MinFx, and the grid cells with black dots are significant at the 5\% level based on the student's t test. It is noted that the experiments in Panel (d) has the fixed SM in August, which suppressed the SM "memory" from July to August

southern China (HHR), an upward (downward) motion corresponds to the increase (decrease) of rainfall in August. When the July SM is small over southern China, the opposite results can be obtained.

In order to examine whether the August rainfall change is a response to the July SM anomalies, five sets of numerical 
experiments were conducted through using the WRF model, including one set of control experiments and four sets of sensitivity experiments. Those experiments were integrated starting at 256 different initial dates during 27 June to 4 July of 1979-2010. Thus, 256 ensemble members are used for analysis to obtain the results. The climatology of rainfall and the atmospheric circulation during July-August was also evaluated over eastern China for the model. It is found that the WRF model can generally simulate the rainfall pattern over eastern China, though its rain belt has larger values and is farther north than that in the observations. For the circulation, the WRF model can well reproduce the atmospheric circulation over eastern China during July and August.

In the comparison of the sensitivity experiments between MaxFr and MinFr, the mechanism is explored and a conceptual diagram is provided in Fig. 11. When the July SM is increased over southern China, the surface latent heat or evapotranspiration increases in August due to the SM "memory". Thus, the surface air moisture increases over southern
China. Due to the upward motion and instability background of monsoon (upward motion of wind and $-\frac{\partial \theta}{\partial p}<0$ in Fig. 9a), the increased water vapor is then transported to the upper levels by the monsoon circulation. This increases latent heat release in the atmosphere over southern China. After that, a cyclonic horizontal circulation forms between 850 and $500 \mathrm{hPa}$ over eastern China, which further induces the convergence of air moisture over southern China. Moreover, this cyclonic circulation can also increase (decrease) the transport of water vapor to southern China (HHR). The increase of the water vapor transport can further enhance the cyclonic circulation over eastern China, which can benefit the air moisture convergence and latent heat release in the atmosphere over southern China. At last, a positive feedback process is formed between water vapor transport and cyclonic circulation over eastern China. During this process, the upward motion over southern China leads to a downward motion over HHR, and the cyclonic circulation causes the

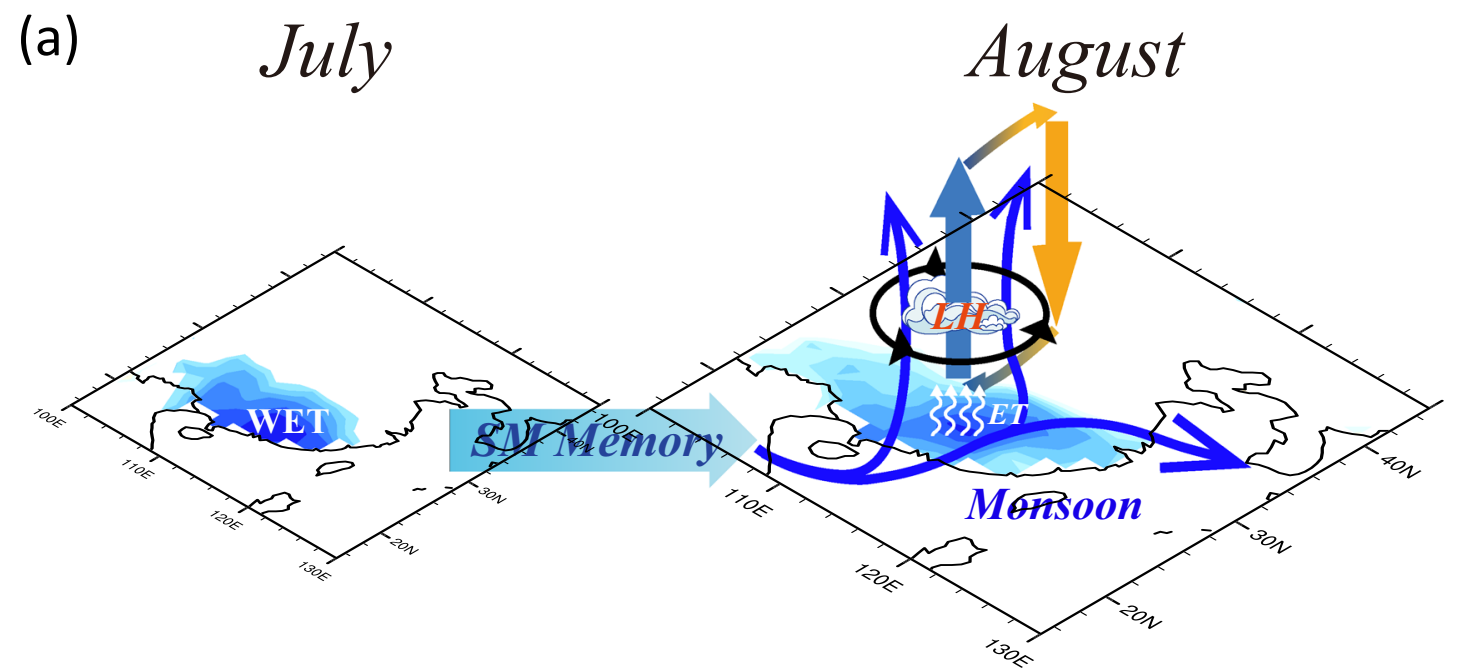

(b)

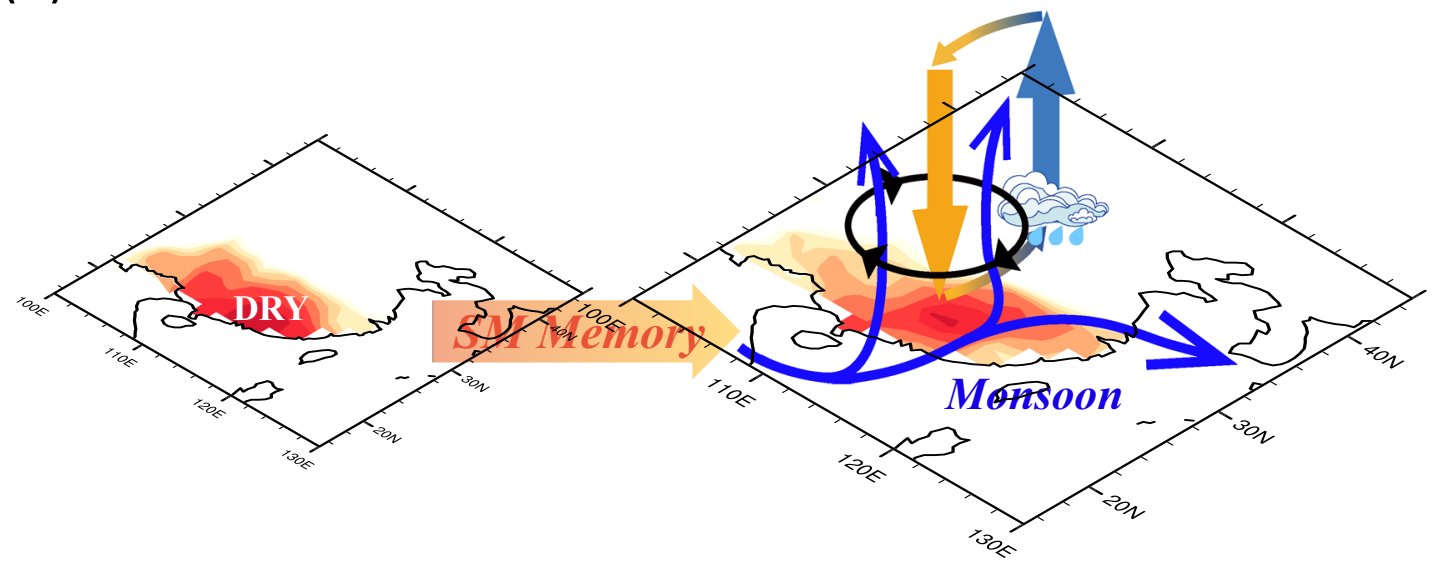

Fig. 11 Mechanism of effects of July SM over southern China on August rainfall over HHR. a Wet and b dry soil over southern China 
air moisture divergence over HHR. The divergence of water vapor and downward motion are not in favor of rainfall over HHR. When the July SM over southern China is dry, similar results are obtained but on the opposite. Those results derived from the sensitivity experiments are generally consistent with those from the observations. The experiments of MaxFx and MinFx further prove that the rainfall anomalies in August are closely related to the SM in July.

In July, there is a dipole pattern of SM over eastern China in the SVD, but only the effect of SM over southern China is examined in the present study. This dipole pattern may have more impact on the August rainfall over HHR than the SM over southern China, but which needs further studies. It is also noted that in the SVD analysis, the relationship between the July SM over southern China and the August precipitation over southern China is not as strong as that in the sensitivity experiments. The vertical and horizontal circulations in the model are not exactly alike to the observations. Those are probably because the relationship between the SM and precipitation could be disturbed by other signals in the observations, which are not considered in the sensitivity experiments. Moreover, the model rain belt is farther north than the observations to the east of $115^{\circ} \mathrm{E}$, which causes the differences of precipitation between MaxFr and MinFr farther west than those in the observations. It should note that SM from subsurface to root zone could be the major source of SM "memory". However, in the present study, we analyzed SM at a shallow depth near the land surface due to the following reasons. (1) The quality of the SM data is much better near the surface than underground. (2) The surface SM directly interacts with the atmosphere. (3) The variation of surface SM can reflect those from subsurface to root zone. In general, this study suggests a significant response of the August precipitation over HHR to the July SM over southern China and further demonstrates the important role played by the SM "memory" on monthly scale. The effects of SM at deep layers on rainfall can be explored by future studies.

Acknowledgements Haishan Chen appreciates the support from the National Natural Science Foundation of China (Grant No. 41625019). Yang Zhou thanks the support from the National Natural Science Foundation of China (Grant No. 42175030) and the Startup Foundation for Introducing Talent of NUIST. We thank the anonymous reviewers for their insightful comments.

Open Access This article is licensed under a Creative Commons Attribution 4.0 International License, which permits use, sharing, adaptation, distribution and reproduction in any medium or format, as long as you give appropriate credit to the original author(s) and the source, provide a link to the Creative Commons licence, and indicate if changes were made. The images or other third party material in this article are included in the article's Creative Commons licence, unless indicated otherwise in a credit line to the material. If material is not included in the article's Creative Commons licence and your intended use is not permitted by statutory regulation or exceeds the permitted use, you will need to obtain permission directly from the copyright holder. To view a copy of this licence, visit http://creativecommons.org/licenses/by/4.0/.

\section{References}

Betts AK, Ball JH, Beljaars ACM, Miller MJ, Viterbo P (1994) Coupling between land-surface boundary-layer parameterizations and rainfall on local and regional scales: lessons from the wet summer of 1993. In Fifth Symp. on Global Change Studies (pp. 174-181).

Cioni G, Hohenegger C (2017) Effect of soil moisture on diurnal convection and precipitation in large-eddy simulations. J Hydrometeorol 18(7):1885-1903. https://doi.org/10.1175/jhm-d-16-0241.1

Cressman GP (1959) An operational objective analysis system. Mon Weather Rev 87(10):367-374. https://doi.org/10.1175/15200493(1959)0872.0.CO;2

Dai YJ, Zeng XB, Dickinson RE, Baker I, Yang ZL (2003) The common land model. Bull Am Meteor Soc 84(8):1013-1023. https:// doi.org/10.1175/BAMS-84-8-1013

Dee DP, Uppala SM, Simmons AJ, Berrisford P, Poli P, Kobayashi S, Andrae U, Balmaseda, MA, Balsamo G, Bauer P, Bechtold P, Beljaars ACM, van de Berg L, Bidlot J, Bormann N, Delsol C, Dragani R, Fuentes M, Geer AJ, Haimberger L, Healy SB, Hersbach H, Hólm EV, Isaksen L, Kallberg P, Köhler M, Matricardi M, McNally AP, Monge-Sanz BM, Morcrette JJ, Park BK, Peubey C, de Rosnay P, Tavolato C, Thépaut JN, Vitart F (2011) The ERA-Interim reanalysis: Configuration and performance of the data assimilation system. Q J R Meteorol Soc 137(656): 553-597. https://doi.org/10.1002/qj.828

Dirmeyer PA, Schlosser CA, Brubaker KL (2009) Precipitation, recycling, and land memory: an integrated analysis. J Hydrometeorol 10(1):278-288. https://doi.org/10.1175/2008jhm1016.1

Douville, H. (2002). Influence of soil moisture on the Asian and African monsoons. Part II: Interannual variability. J Clim 15(7), 701-720. https://doi.org/10.1175/1520-0442(2002)015<0701: IOSMOT $>2.0 . \mathrm{CO} ; 2$

Douville H, Chauvin F., and Broqua, H. (2001). Influence of soil moisture on the Asian and African monsoons. Part I: mean monsoon and daily precipitation. J Clim, 14(11), 2381-2403. https:// doi.org/10.1175/1520-0442(2002)0152.0.CO;2

Entin JK, Robock A, Vinnikov KY, Hollinger SE, Liu S, Namkhai A (2000) Temporal and spatial scales of observed soil moisture variations in the extratropics. J Geophys Res 105(D9):1186511877. https://doi.org/10.1029/2000JD900051

Gao Y, Leung LR, Zhao C, Hagos S (2017) Sensitivity of US summer precipitation to model resolution and convective parameterizations across gray zone resolutions. J Geophys Res 122(5):2714-2733

Gao C, Li G, Xu B (2020a) Weakening influence of spring soil moisture over the indo-china peninsula on the following summer meiyu front and precipitation extremes over the Yangtze River Basin. J Clim 33(23): 10055-10072

Gao C, Li G, Xu B, Li X (2020b) Effect of spring soil moisture over the Indo-China Peninsula on the following summer extreme precipitation events over the Yangtze River basin. Clim Dyn 54(9):3845-3861

Giorgi F, Coppola E, Solmon F, Mariotti L, Sylla MB, Bi X, Elguindi N, Diro GT, Nair V, Giuliani G, Turuncoglu UU, Cozzini S, Güttler I, O'Brien TA, Tawfik AB, Shalaby A, Zakey AS, Steiner AL, Stordal F, Sloan LC, Brankovic C (2012) RegCM4: model description and preliminary tests over multiple CORDEX domains. Clim Res 52:7-29. https://doi.org/10.3354/cr01018

Grell GA, Freitas SR (2014) A scale and aerosol aware stochastic convective parameterization for weather and air quality modeling. 
Atmos Chem Phys 14(10):5233-5250. https://doi.org/10.5194/ acp-14-5233-2014

Hong SY, Lim JOJ (2006) The WRF single-moment 6-class microphysics scheme (WSM6). Journal of the Korean Meteorological Society 42(2):129-151

Hong SY, Noh Y, Dudhia J (2006) A new vertical diffusion package with an explicit treatment of entrainment processes. Mon Weather Rev 134(9):2318-2341. https://doi.org/10.1175/MWR3199.1

Huang B, Polanski S, Cubasch U (2015) Assessment of precipitation climatology in an ensemble of CORDEX-East Asia regional climate simulations. Climate Res 64(2):141-158. https://doi.org/10. 1175/JCLI-D-11-00375.1

Huffman GJ, Bolvin DT, Nelkin EJ, Wolff DB, Adler RF, Gu G, Hong Y, Bowman KP, Stocker EF (2007) The TRMM multisatellite precipitation analysis (TMPA): Quasi-global, multiyear, combinedsensor precipitation estimates at fine scales. J Hydrometeorol 8(1):38-55. https://doi.org/10.1175/JHM560.1

Jin Q, Wei J, Yang ZL, Pu B, Huang J (2015) Consistent response of Indian summer monsoon to Middle East dust in observations and simulations. Atmos Chem Phys 15(17):9897-9915

Klein C, Heinzeller D, Bliefernicht J, Kunstmann H (2015) Variability of West African monsoon patterns generated by a WRF multiphysics ensemble. Clim Dyn 45(9):2733-2755

Koster RD, Chang Y, Schubert SD (2014) A mechanism for landatmosphere feedback involving planetary wave structures. J Clim 27(24):9290-9301. https://doi.org/10.1175/JCLI-D-14-00315.1

Koster RD, Chang Y, Wang H, Schubert SD (2016) Impacts of local soil moisture anomalies on the atmospheric circulation and on remote surface meteorological fields during boreal summer: a comprehensive analysis over North America. J Clim 29(20):73457364. https://doi.org/10.1175/jcli-d-16-0192.1

Koster, R. D., Dirmeyer, P. A., Guo, Z., Bonan, G., Chan, E., Cox, P., Gordon, C. T., Kanae, S., Kowalczyk, E., Lawrence, D., Liu, P., Lu, C-H., Malyshev, S., McAvaney, B., Mitchell, K., Mocko, D., Oki, T., Oleson, K., Pitman, A., Sud, Y. C., Taylor, C. M., Verseghy, D., Vasic, R., Xue, Y. K., and Yamada, T. (2004). Regions of strong coupling between soil moisture and precipitation. Science, 305(5687). 1138-1140. https://doi.org/10.1126/ science. 1100217

Koster RD, Schubert SD, Suarez MJ (2009) Analyzing the concurrence of meteorological droughts and warm periods, with implications for the determination of evaporative regime. J Clim 22(12):33313341. https://doi.org/10.1175/2008jcli2718.1

Lawrence DM, Oleson KW, Flanner MG, Thornton PE, Swenson SC, Lawrence PJ, Zeng X, Yang Z, Levis S, Sakaguchi K, Bonan GB, Slater AG (2011) Parameterization improvements and functional and structural advances in version 4 of the community Land Model. J Adv Modeling Earth Syst 3(1):M03001. https://doi.org/ 10.1029/2011MS00045

Liu D, Yu Z, Mishra AK (2017a) Evaluation of soil moisture-precipitation feedback at different time scales over Asia. Int J Climatol 37(9):3619-3629. https://doi.org/10.1002/joc.4943

Liu L, Zhang R, Zuo Z (2017b) Effect of Spring Precipitation on Summer Precipitation in Eastern China: Role of Soil Moisture. J Clim 30(22):9183-9194. https://doi.org/10.1175/JCLI-D-17-0028.1

Liu W, Chen H, Yu M (2019) Impacts of cumulus convective parameterization schemes on simulation of East Asian summer circulation and rainfall. Chin J Atmosp Sci (in Chinese) 43(1):64-74

Meng L, Long D, Quiring SM, Shen Y (2014) Statistical analysis of the relationship between spring soil moisture and summer precipitation in East China. Int J Climatol 34(5):1511-1523. https://doi. org/10.1002/joc. 3780

Mlawer EJ, Taubman SJ, Brown PD, Iacono MJ, Clough SA (1997) Radiative transfer for inhomogeneous atmospheres: RRTM, a validated correlated-k model for the longwave. J Geophys Res 102(D14):16663-16682. https://doi.org/10.1029/97JD00237
Mugume I, Waiswa D, Mesquita MDS, Reuder J, Basalirwa C, Bamutaze Y, Ayesiga G (2017) Assessing the performance of WRF model in simulating rainfall over western Uganda. J Climatol Weather Forecasting 5(1):1-9

North GR, Bell TL, Cahalan RF, Moeng FJ (1982) Sampling errors in the estimation of empirical orthogonal functions. Mon Weather Rev 110(7):699-706. https://doi.org/10.1175/1520-0493(1982) 110\%3c0699:seiteo\%3e2.0.co;2

Saha S, Moorthi S, Pan HL, Wu X, Wang J, Nadiga S, Tripp P, Kistler R, Woollen J, Behringer D, Liu H, Stokes D, Grumbine R, Gayno G, Wang J, Hou Y-T, Chuang H-Y, Juang H-MH, Sela J, Iredell M, Treadon R, Kleist D, Delst PV, Keyser D, Derber J, Ek M, Meng J, Wei H, Yang R, Lord S, Dool HVD, Kumar A, Wang W, Long C, Chelliah M, Xue Y, Huang B, Schemm JK, Ebisuzaki W, Lin R, Xie P, Chen M, Zhou S, Higgins W, Zou C-Z, Liu Q, Chen Y, Han Y, Cucurull L, Reynolds RW, Rutledge G, Goldberg M (2010) The NCEP climate forecast system reanalysis. Bull Am Meteor Soc 91(8):1015-1058. https://doi.org/10.1007/s00382-010-0954-4

Seneviratne SI, Corti T, Davin EL, Hirschi M, Jaeger EB, Lehner I, Orlowsky B, Teuling AJ (2010) Investigating soil moisture-climate interactions in a changing climate: a review. Earth Sci Rev 99(3-4):125-161. https://doi.org/10.1016/j.earscirev.2010.02.004

Skamarock WC, Klemp JB, Dudhia J, Gill DO, Barker DM, Wang W, Powers JG (2008) A description of the Advanced Research WRF version 3. NCAR Technical note-475+ STR, $123 \mathrm{pp}$.

Shi P, Lu H, Leung LR, He Y, Wang B, Yang K, Yu L, Liu L, Huang W, Xu S, Liu J, Huang X, Li L, Lin Y (2021) Significant land contributions to interannual predictability of East Asian summer monsoon rainfall. Earth's Future, 9(2), e2020EF001762.

Smolarkiewicz PK, Grell GA (1992) A class of monotone interpolation schemes. J Comput Phys 101(2):431-440

Trenberth KE (1991) Climate diagnostics from global analyses: conservation of mass in ECMWF analyses. J Clim 4(7):707-722. https:// doi.org/10.1175/1520-0442(1991)004\%3c0707:CDFGAC\%3e2.0. $\mathrm{CO} ; 2$

Wang D, Menz C, Simon T, Simmer C, Ohlwein C (2013) Regional dynamical downscaling with CCLM over East Asia. Meteorol Atmos Phys 121(1-2):39-53. https://doi.org/10.1007/ s00703-013-0250-z

Wei J, Dirmeyer PA (2012) Dissecting soil moisture-precipitation coupling. Geophys Res Lett 39(19):L19711. https://doi.org/10.1029/ 2012GL052351

Yanai M, Esbensen S, Chu JH (1973) Determination of bulk properties of tropical cloud clusters from large-scale heat and moisture budgets. J Atmos Sci 30(4):611-627. https://doi.org/10.1175/ 1520-0469(1973)030,0611:DOBPOT.2.0.CO;2

Zeng D, Yuan X (2018) Multiscale land-atmosphere coupling and its application in assessing subseasonal forecasts over East Asia. J Hydrometeorol 19(5):745-760. https://doi.org/10.1175/ JHM-D-17-0215.1

Zhan Y, Lin Z (2011) The relationship between June precipitation over mid-lower reaches of the Yangtze River basin and spring soil moisture over the East Asian monsoon region. Acta Meteor Sin 25(3):355-363. https://doi.org/10.1007/s13351-011-0310-6

Zhang, R., and Zuo, Z. (2011). Impact of spring soil moisture on surface energy balance and summer monsoon circulation over East Asia and precipitation in East China. J Clim 24(13), 3309-3322. https://doi.org/10.1175/2011JCLI4084.1

Zhang C, Hendon HH (1997) On propagating and stationary components of the intraseasonal oscillation in tropical convection. J Atmosp Sci 54:741-752. https://doi.org/10.1175/15200469(1997)054\%3c0741:PASCOT\%3e2.0.CO;2

Zhong S, Yang T, Qian Y, Zhu J, Wu F (2018) Temporal and spatial variations of soil moisture-Precipitation feedback in East China during the East Asian summer monsoon period: a sensitivity 
study. Atmos Res 213:163-172. https://doi.org/10.1016/j.atmos res.2018.05.014

Zhu S, Qi Y, Chen H et al (2021) Distinct impacts of spring soil moisture over the Indo-China Peninsula on summer precipitation in the Yangtze River basin under different SST backgrounds. Clim Dyn 56:1895-1918

Zhou J, Zuo Z, Rong X (2020) Comparison of the effects of soil moisture and El Niño on summer precipitation in eastern China. Sci China Earth Sci 63(2):267-278
Zuo Z, Zhang R (2016) Influence of soil moisture in eastern China on the East Asian summer monsoon. Adv Atmos Sci 33(2):151-163

Publisher's Note Springer Nature remains neutral with regard to jurisdictional claims in published maps and institutional affiliations. 